\title{
Characterization of Lgr5+ Progenitor Cell Transcriptomes after Neomycin Injury in the Neonatal Mouse Cochlea
}

\author{
Shasha Zhang ${ }^{1,2,3}$, Yuan Zhang ${ }^{1}$, Pengfei $\mathrm{Yu}^{4}$, Yao Hu${ }^{5}$, Han Zhou 6 , Lingna Guo ${ }^{1}$, \\ Xiaochen $X u^{1}$, Xiaocheng Zhu ${ }^{6}$, Muhammad Waqas ${ }^{1,7}$, Jieyu Qi ${ }^{1}$, Xiaoli Zhang ${ }^{6}$, Yan Liu ${ }^{5}$, \\ Fangyi Chen ${ }^{8}$, Mingliang Tang ${ }^{1}$, Xiaoyun Qian ${ }^{6}$, Haibo Shi ${ }^{9 *}, \mathrm{Xia} \mathrm{Gao}^{2,6 *}$ and \\ Renjie Chai ${ }^{1,2,3 *}$

\begin{abstract}
${ }^{1}$ Key Laboratory for Developmental Genes and Human Disease, Ministry of Education, Institute of Life Sciences, Southeast University, Nanjing, China, ${ }^{2}$ Research Institute of Otolaryngology, Nanjing, China, ${ }^{3}$ Co-innovation Center of Neuroregeneration, Nantong University, Nantong, China, ${ }^{4}$ Bioinformatics Department, Admera Health LLC, South Plainfield, NJ, United States, ${ }^{5}$ School of Pharmacy, Institute for Stem Cell and Neural Regeneration, Nanjing Medical University, Nanjing, China, ${ }^{6}$ Jiangsu Provincial Key Medical Discipline (Laboratory), Department of Otolaryngology Head and Neck Surgery, Affiliated Drum Tower Hospital of Nanjing University Medical School, Nanjing, China, ${ }^{7}$ Department of Biotechnology, Federal Urdu University of Arts, Science and Technology, Karachi, Pakistan, ${ }^{8}$ Department of Biomedical Engineering, Southern University of Science and Technology, Shenzhen, China, ${ }^{9}$ Department of Otorhinolaryngology Head and Neck Surgery, The Sixth People's Hospital Affiliated to Shanghai Jiao Tong University, Shanghai, China
\end{abstract}

OPEN ACCESS

Edited by:

Hong-Bo Zhao,

University of Kentucky, United States

Reviewed by:

Esperanza Bas Infante,

University of Miami, United States

Jun Aruga,

Nagasaki University, Japan

*Correspondence:

Haibo Shi

haibo99@hotmail.com

Xia Gao

xiagao@aliyun.com

Renjie Chai

renjiec@seu.edu.cn

Received: 28 April 2017 Accepted: 16 June 2017

Published: 04 July 2017

Citation:

Zhang S, Zhang Y, Yu P, Hu Y, Zhou H,

Guo L, XuX, ZhuX, Waqas M, Qi J,

Zhang $X$, Liu Y, Chen F, Tang M,

Qian X, Shi H, Gao $X$ and Chai $R$ (2017) Characterization of Lgr5+

Progenitor Cell Transcriptomes after Neomycin Injury in the Neonatal Mouse Cochlea.

Front. Mol. Neurosci. 10:213. doi: 10.3389/fnmol.2017.00213
Lgr5+ supporting cells (SCs) are enriched hair cell $(\mathrm{HC})$ progenitors in the cochlea. Both in vitro and in vivo studies have shown that $\mathrm{HC}$ injury can spontaneously activate Lgr5+ progenitors to regenerate HCs in the neonatal mouse cochlea. Promoting HC regeneration requires the understanding of the mechanism of $\mathrm{HC}$ regeneration, and this requires knowledge of the key genes involved in $\mathrm{HC}$ injury-induced self-repair responses that promote the proliferation and differentiation of Lgr5+ progenitors. Here, as expected, we found that neomycin-treated Lgr5+ progenitors (NLPS) had significantly greater $\mathrm{HC}$ regeneration ability, and greater but not significant proliferation ability compared to untreated Lgr5+ progenitors (ULPS) in response to neomycin exposure. Next, we used RNA-seq analysis to determine the differences in the gene-expression profiles between the transcriptomes of NLPs and ULPs from the neonatal mouse cochlea. We first analyzed the genes that were enriched and differentially expressed in NLPS and ULPs and then analyzed the cell cycle genes, the transcription factors, and the signaling pathway genes that might regulate the proliferation and differentiation of Lgr5+ progenitors. We found 9 cell cycle genes, 88 transcription factors, 8 microRNAs, and 16 cell-signaling pathway genes that were significantly upregulated or downregulated after neomycin injury in NLPs. Lastly, we constructed a protein-protein interaction network to show the interaction and connections of genes that are differentially expressed in NLPs and ULPs. This study has identified the genes that might regulate the proliferation and $\mathrm{HC}$ regeneration of $\mathrm{Lgr} 5+$ progenitors after neomycin injury, and investigations into the roles and mechanisms of these genes in the cochlea should be performed in the future to identify potential therapeutic targets for $\mathrm{HC}$ regeneration.

Keywords: neomycin, hair cell injury, mRNA-Seq, hair cell regeneration, supporting cell, proliferation, differentiation, gene expression 


\section{INTRODUCTION}

Sensory hair cells (HCs) in the inner ear are specialized mechanoreceptors for sound recognition. Damage to these HCs leads to sensorineural hearing loss, which is one of the most common sensory disorders affecting millions of children and adults around the world (Duthey, 2013). HC damage is irreparable in adult mammals due to the absence of cochlear $\mathrm{HC}$ regeneration, and this results in permanent hearing loss. In contrast, the supporting cells (SCs) located within the auditory and vestibular system of non-mammalian animals such as birds and fish retain the ability to proliferate and regenerate HCs in response to both internal and external auditory/vestibular damage (Corwin and Cotanche, 1988; Balak et al., 1990; Stone and Cotanche, 2007; Ma et al., 2008; Warchol, 2011). Several recent studies have shown that a subset of SCs expressing Lgr5 can act as progenitor cells in the mammalian cochlea, and these cells possess limited regenerative capacity during the early postnatal period (Bermingham-McDonogh and Reh, 2011; Chai et al., 2011, 2012; Shi et al., 2013; Bramhall et al., 2014; Cox et al., 2014; Waqas et al., 2016a). HC injury in the neonatal mouse cochlea can initiate self-repair processes that involve the spontaneous regeneration of HCs from these Lgr5+ progenitors, and this has been demonstrated both in vitro and in vivo (Bramhall et al., 2014; Cox et al., 2014). However, this regenerative ability is lost as the mice age and disappears completely by the time they reach adulthood (White et al., 2006; Oesterle et al., 2008; Cox et al., 2014).

In the organ of Corti, the specific arrangement of SCs and sensory HCs is not only necessary to maintain the mosaiclike structure, but the SCs might also serve as a reservoir for regenerating HCs after damage (Li et al., 2003; Lee et al., 2006; Sinkkonen et al., 2011; Cox et al., 2014; Li W. et al., 2015). Although the resident SCs in the cochlea are postmitotic by nature or due to the complex organization of the organ of Corti (Malgrange et al., 2002; Waqas et al., 2016b), these SCs can be cultivated in vitro and have been shown to form floating spheres with the ability to differentiate into various cell types of the inner ear, including HCs (Oshima et al., 2007a; Martinez-Monedero et al., 2008; Wang T. et al., 2015). In vitro and in vivo regulation of key developmental factors such as Wnt (Malgrange et al., 2002; Yamamoto et al., 2006; Shi et al., 2013; Liu L. et al., 2016), Notch (Li et al., 2003; Doetzlhofer et al., 2009; Kelly et al., 2012; Ni et al., 2016), and Atoh1 (Zheng and Gao, 2000; Shi et al., 2012; Kuo et al., 2015) in these SCs can stimulate the increased formation of myosin7a+ HCs. In addition, studies have shown that upon cochlear HC damage, non-sensory SCs/progenitors display at least some capacity to proliferate and mitotically regenerate HCs as a self-repair response (Li et al., 2003; Cox et al., 2014). To better understand the HC regeneration mechanism and to develop strategies to promote $\mathrm{HC}$ regeneration in adult mammals, it is important to identify the key genes involved in the HC injury-induced self-repair response, including proliferation of SCs/progenitors and their differentiation into HCs.

Lgr5 is a downstream target gene of the Wnt pathway and is a marker for adult stem cells that is expressed in a subpopulation of cochlear SCs (Chai et al., 2011). In the inner ear, Lgr5+ progenitors exist in a quiescent state, but they have been shown to proliferate and regenerate HCs via both mitotic division and direct transdifferentiation after HC injury (Madisen et al., 2010; Chai et al., 2012; Bramhall et al., 2014; Cox et al., 2014). Genetic ablation of HCs in vivo stimulates the Lgr5+ progenitors to acquire the HC fate in all three cochlear turns but with significantly higher frequency in the apex compared to the base (Cox et al., 2014). Similarly, in the in vitro ototoxic damage model, the new HCs originate from the Lgr5+ progenitors that are present in the organotypic culture of the neonatal cochlea (Bramhall et al., 2014). These studies have demonstrated that damage to the neonatal cochlea results in regeneration of HCs initiated by the Lgr5+ progenitors. Our previous work also demonstrated that after neomycin injury the Wnt signaling pathway is activated in the cochlea as part of the repair process (Kelly et al., 2012), but the key genes involved in neomycin injury-induced self-repair responses have not yet been identified. It is important to understand the detailed molecular mechanism regulating the ability of Lgr5+ progenitor cells to proliferate and regenerate HCs after neomycin injury because this might provide new targets for stimulating these Lgr5+ progenitors to regenerate more HCs after ototoxic damage and to restore hearing.

In this study, we explored the molecular mechanism behind the proliferation and HC regeneration capacity of Lgr5+ progenitors after neomycin damage. We found that after neomycin treatment, Lgr5+ progenitors located within the neonatal cochlea showed a significantly greater ability to proliferate and regenerate HCs. We further performed RNA-seq profiling of the Lgr5+ progenitors in order to determine the genes involved in regulating proliferation and $\mathrm{HC}$ regeneration after neomycin treatment. Finally, we predicted the function of the differentially expressed genes involved in inner ear HC regeneration using the STRING bioinformatics tool to construct a protein-protein interaction network. These datasets are expected to systematically explain the detailed regulatory mechanisms of Lgr5+ progenitors in HC regeneration after neomycin damage.

\section{MATERIALS AND METHODS}

\section{Animals and Genotyping PCR}

Lgr5-EGFP-IRES-creERT2 mice (Stock \#008875, Jackson Laboratory) and Rosa26-tdTomato reporter mice (Stock \#007914, Jackson Laboratory) of either sex were used in the experiments (Pannier et al., 2009). We performed all animal procedures according to protocols that were approved by the Animal Care and Use Committee of Southeast University and were consistent with the National Institute of Health's Guide for the Care and Use of Laboratory Animals. We made all efforts to minimize the number of animals used and to prevent their suffering.

The tail tips were collected from transgenic mice, and genomic DNA was obtained by adding $180 \mu 150 \mathrm{mM} \mathrm{NaOH}$, incubating at $98^{\circ} \mathrm{C}$ for $60 \mathrm{~min}$, and adding $20 \mu \mathrm{l} 1 \mathrm{M}$ Tris- $\mathrm{HCl}(\mathrm{PH} 7.0)$. The genotyping PCR was carried out by using $2 \times$ Tag Master Mix (Vazyme), and the PCR protocol was as follows: $94^{\circ} \mathrm{C}$ for $3 \mathrm{~min}$; 37 cycles of $94^{\circ} \mathrm{C}$ for $30 \mathrm{~s}, 60^{\circ} \mathrm{C}$ for $30 \mathrm{~s}$, and $72^{\circ} \mathrm{C}$ for $45 \mathrm{~s} ; 72^{\circ} \mathrm{C}$ 
for $5 \mathrm{~min}$; and holding at $4^{\circ} \mathrm{C}$. The genotyping primers were as follows: Lgr5 (F) CTG CTC TCT GCT CCC AGT CT, wild-type (R) ATA CCC CAT CCC TTT TGA GC, mutant (R) GAA CTT CAG GGT CAG CTT GC; tdTomato wild-type (F) AAG GGA GCT GCA GTG GAG T, (R) CCG AAA ATC TGT GGG AAG TC; mutant (F) GGC ATT AAA GCA GCG TAT C, (R) CTG TTC CTG TAC GGC ATG G.

\section{In vitro Lineage Tracing of Lgr5+ Cells in the Neomycin-Damaged and Undamaged Cochleae}

Heterozygous Lgr5-EGFP-creERT2 mice were crossed with homozygous Rosa26-tdTomato mice to trace the fate of Lgr5+ cells in the neomycin-damaged and undamaged cochleae. Postnatal day (P)1 mice were sacrificed, and the cochleae from Lgr5-EGFP-creER/Rosa26-tdTomato double-positive mice were dissected out and cultured in DMEM/F12 medium supplemented with N2 (1:100 dilution, Invitrogen), B27 (1:50 dilution, Invitrogen), heparin sulfate $(50 \mathrm{ng} / \mathrm{ml}$, Sigma), and the growth factors bFGF (10 ng/ml, Sigma), EGF (20 ng/ml, Sigma), and IGF-1 (50 ng/ml, Sigma) (full medium). The cochleae were treated with $500 \mathrm{nM} 4 \mathrm{OH}$-tamoxifen for 4 days all through the culture. At $12 \mathrm{~h}$ after the beginning of the culture, the cochleae were treated with $0.5 \mathrm{mM}$ neomycin (Sigma) or PBS for $12 \mathrm{~h}$. EdU was added to the medium at a final concentration of $10 \mu \mathrm{M}$ to label dividing cells. The damaged and undamaged cochleae were examined after 4 days of culture.

\section{Isolation of Lgr5+ Cells via Flow Cytometry} Approximately 30-40 postnatal day (P)1-2 Lgr5-EGFP-creERT2 mice were sacrificed, and the cochleae were dissected out and cultured in full medium as described above and allowed to recover for a few hours. The cochleae were treated with $0.5 \mathrm{mM}$ neomycin (Sigma) or PBS for $12 \mathrm{~h}$ and then allowed to recover in full medium for $24 \mathrm{~h}$. The cochleae were collected and trypsinized by prewarmed $0.125 \%$ trypsin/EDTA (Invitrogen) at $37^{\circ} \mathrm{C}$ for $8 \mathrm{~min}$. The same amount of soybean trypsin inhibitor $(10 \mathrm{mg} / \mathrm{ml}$, Worthington Biochem) was then added to terminate the trypsin reaction in the neomycin-damaged and undamaged cochlear samples. Cochleae were separated into single cells by pipetting up and down 80-100 times with blunt tips and then percolating through a $40 \mu \mathrm{m}$ cell strainer (BD Biosciences). Dissociated cells from damaged and undamaged cochleae were sorted on a BD FACS Aria III using the GFP channel.

\section{Real-Time PCR}

Total RNA was extracted from $\sim 20,000$ FACS-sorted neomycintreated Lgr5+ progenitors (NLPs) and 20,000 untreated Lgr5+ progenitors (ULPs) with an RNeasy micro kit (QIAGEN). RevertAid First Strand cDNA Synthesis Kit (Thermo) was used to synthesize cDNA. Real-time PCR was carried out by using the SYBR Green PCR Master Mix (Roche) on a BIO-RAD C1000 Touch thermal cycler (BIO-RAD). Each $25 \mu \mathrm{L}$ PCR reaction mixture contained $12.5 \mu \mathrm{L} 2 \times$ SYBR Green PCR Master Mix, $0.5 \mu \mathrm{L}$ forward primer $(10 \mu \mathrm{M}), 0.5 \mu \mathrm{L}$ reverse primer $(10$ $\mu \mathrm{M}), 2 \mu \mathrm{L}$ template, and $9.5 \mu \mathrm{L}$ sterilized distilled water. Each group contained three samples, and each PCR was carried out in triplicate. The PCR protocol was as follows: $50^{\circ} \mathrm{C}$ for $2 \mathrm{~min}$; $95^{\circ} \mathrm{C}$ for $10 \mathrm{~min}$; 45 cycles of $95^{\circ} \mathrm{C}$ for $15 \mathrm{~s}, 60^{\circ} \mathrm{C}$ for $1 \mathrm{~min}$; and a melting curve was performed starting at 65 up to $95^{\circ} \mathrm{C}$ with an increase of $0.5^{\circ} \mathrm{C}$ per $1 \mathrm{~s}$ to verify primer specificities. Expression levels of each gene was normalized to the GAPDH in the same samples. The primers were listed in Table $\mathbf{1}$.

\section{Immunostaining and Image Acquisition}

Neomycin-damaged and undamaged cochleae were fixed in $4 \%$ PFA for $1 \mathrm{~h}$ at room temperature, washed with PBS, blocked with blocking solution ( $5 \%$ donkey serum, $0.5 \%$ Triton X100, $0.02 \%$ sodium azide, and $1 \%$ bovine serum albumin in $\mathrm{pH} 7.4$ PBS) for $1 \mathrm{~h}$ at room temperature and then incubated with primary antibodies diluted in PBT1 (2.5\% donkey serum, $0.1 \%$ Triton X100, 0.02\% sodium azide, and $1 \%$ bovine serum albumin in $\mathrm{pH} 7.4 \mathrm{PBS}$ ) at $4^{\circ} \mathrm{C}$ for overnight. This was followed by washing with $0.1 \%(\mathrm{v} / \mathrm{v})$ Triton $\mathrm{X} 100$ in $\mathrm{pH} 7.4$ PBS three times and incubating with fluorescence-conjugated secondary antibody for $1 \mathrm{~h}$ at room temperature. After washing with $0.1 \%$ (v/v) Triton $\mathrm{X} 100$ in $\mathrm{pH} 7.4$ PBS three times, the cochleae were mounted in antifade fluorescence mounting medium (DAKO). Anti-Myosin7a (Proteus Bioscience, \#25-6790, 1:1,000 diluted in PBT1) and anti-Sox2 (Santa Cruz Biotechnology, \#17320, 1:400 diluted in PBT1) primary antibodies were used. Donkey anti-rabbit Alexa Fluor 555 and 647 fluorescenceconjugated secondary antibodies (Invitrogen, \#A-31572, \#A31573) were used for Myo7a, and donkey anti-goat Alexa Fluor 647 fluorescence-conjugated secondary antibody (Invitrogen, \#A-21447) was used for Sox2. All the fluorescent secondary antibodies were diluted 1:400 in PBT2 (0.1\% Triton X100 and $1 \%$ bovine serum albumin in $\mathrm{pH} 7.4 \mathrm{PBS})$. The Click-it EdU imaging kit (Invitrogen) was used after blocking to measure cell proliferation. The fluorescence images were obtained with a Zeiss LSM 710 confocal microscope and were analyzed using ImageJ (NIH) and Photoshop CS5 (Adobe Systems).

\section{RNA Extraction for RNA-Seq}

Approximately 20,000 NLPs and 20,000 ULPs were used to extract total RNA with an RNeasy micro kit (QIAGEN). The RNA samples from NLPs and ULPs were split into three fractions for separate replicates.

\section{RNA-Seq}

The double-strand cDNA was synthesized from the total RNA obtained from the NLPs and ULPs using a TruSeq ${ }^{\circledR}$ RNA LT Sample Prep Kit v2 (Illumina). Illumina adapters were ligated to the cDNA molecules after end repair. The ligated cDNA was cleaned up with AmpureBeads (Beckman). The library was amplified using 10 cycles of PCR for the enrichment of adapterligated fragments. Transcriptome sequencing was carried out with the Illumina-Hiseq2500 system (Illumina).

\section{RNA-Seq Data Analysis}

The TopHat (version 1.3.2) and CuffLinks (version 2.2.1) pipeline was used for the alignment and gene expression counting of the RNA-seq data. The reference genome was mm9. The FPKM (Fragments per kilobase of exon per million fragments 
mapped) values of all mouse genes were summarized together for all samples (three NLP samples and three ULP sample). Spearman's rank correlation was calculated for all pair-wise combinations of samples based on the FPKM values of all mouse genes. The correlation plot was generated with the corrplot package in R. A total of 46,983 mouse RefSeq transcripts were included in the RNA-seq data, and the means and standard deviations of the normalized data were calculated. A value of $p<0.05$ was considered statistically significant. The expression levels of all of the transcriptional units were measured according to their FPKM values, and a cutoff level of 0.1 was chosen as the lowest gene expression level. The Gene Ontology (GO) analysis was done with DAVID GO Annotation. The protein-protein interaction information was extracted from the STRING database. The interaction network graph was drawn by Cytoscope 3.4. Important gene lists of different signaling pathways (Wnt, Notch, TGF $\beta$, Hippo) were determined based on information from the KEGG database.

\section{Statistical Analysis}

For each condition, at least three individual experiments were conducted. Data are presented as mean \pm standard errors of the means (SEM), and GraphPad Prism6 software was used to analyze the data. Statistical significance was determined using a two-tailed, unpaired Student's $t$-test. A value of $p<0.05$ was considered statistically significant.

\section{RESULTS}

\section{Neomycin Injury Significantly Increases the HC Regeneration Ability of Lgr5+ Progenitors}

Lgr5+ progenitors can generate HCs in the neonatal mouse cochlea both in vivo and in vitro (Madisen et al., 2010; Chai et al., 2012). Here we performed an in vitro lineage-tracing experiment by crossing Lgr5-EGFP-creER mice with the Rosa26tdTomato reporter strain (Pannier et al., 2009). P1 Lgr5-EGFPcreER/Rosa26-tdTomato double-positive mouse cochleae were dissected out and cultured in full medium with $500 \mathrm{nM} 4 \mathrm{OH}-$ tamoxifen to lineage trace the Lgr5+ progenitors. The cochleae were damaged by neomycin as described in the Section Materials and Methods (Figure 1A). We found that significantly more tdTomato/Myo7a double-positive HCs were generated from NLPs compared to ULPs in all three turns of the cochlea (Figures 1B-D, $p<0.05, n \geqq 4$ ), suggesting that the Lgr5+ progenitors generated significantly more HCs after neomycin injury in vitro.

\section{Neomycin Injury Increases the Proliferation of Lgr5+ Progenitors, but Not Significantly}

To determine the capacity of Lgr5+ progenitors in the damaged and undamaged cochleae to mitotically regenerate HCs, EdU was added to the culture medium from day 0 to day 4 of the culture (Figure 2A). Consistent with previous reports, there were no tdTomato $+/ \mathrm{EdU}+$ cells in the undamaged cochleae (Figures 2B,C). In contrast, tdTomato $+/$ EdU+ cells, which represent the mitotically proliferated Lgr5+ progenitors, could be found in the damaged cochleae (Figure 2C), indicating that neomycin treatment induced the proliferation of Lgr5+ progenitors. However, due to the very small number of tdTomato+/EdU+ cells in neomycin-treated cochleae, the increase was not significant compared to the control group (Figure 2B, $p=0.093, n \geqq 5$ ).

\section{Analysis of RNA-Seq Results}

P1 Lgr5-EGFP-creER mice were sacrificed, and their cochleae were dissected out, cultured in full medium for $12 \mathrm{~h}$, and then treated with $0.5 \mathrm{mM}$ neomycin for $12 \mathrm{~h}$ to damage the HCs. The cochleae were allowed to recover for another $24 \mathrm{~h}$ before trypsinization and cell sorting (Figures 3A,B). After cell sorting, 20,000 isolated NLPs and 20,000 ULPs were collected and RNAseq analysis was performed to determine their gene-expression profiles (supplementary Data Sheet 1). Principal component analysis was performed to assess the reproducibility of the measurements, and the NLP and ULP groups were well-separated by principal component 1 (Figure 3C). After excluding FPKM values below 0.1, 20,362 and 17,123 transcripts were examined separately in the NLPs and ULPs, respectively, and 14,877 transcripts were expressed in both cell populations (Figure 3D).

\section{Genes Enriched in Lgr5+ Progenitors from Neomycin-Damaged and Undamaged Cochleae}

To determine the expression profiles of the richly expressed genes in NLPs and ULPs, the expression levels and abundance rankings of the most abundantly expressed genes were analyzed. Figure 4A shows the expression levels for the top 200 most abundant transcripts in ULPs (blue bars). The expression levels (red bars) and the abundance rankings (red numbers) of the same transcripts in NLPs are also illustrated for comparison. Similarly, Figure 4B shows the 200 most abundant transcripts in NLPs (red bars) compared to expression levels (blue bars) and abundance rankings (blue numbers) of the same transcripts in ULPs. As shown in both figures, most of the transcripts that were abundantly expressed in NLPs were also abundantly expressed in ULPs. However, Gm10800, Net1, Gm28438, Nr4a1, Krt18, Ler2, and Dpysl2 (NLP rank > 1,000) were only richly expressed in ULPs, and Cdkn1a, Ccng1, and Suco (ULP rank > 1,000) were only richly expressed in NLPs.

\section{Differentially Expressed Genes in Lgr5+ Progenitors from Neomycin-Damaged and Undamaged Cochleae}

In order to characterize the genes that are significantly differentially expressed in NLPs and ULPs, we selected the differentially expressed genes in NLPs and ULPs by comparing their expression levels (fold change $>2.0, p<0.05$ ). Figure 5A shows an overall picture of the expressed transcripts in NLPs and ULPs. We found 549 genes that were significantly upregulated and 1,817 genes that were significantly downregulated in the NLPs. Figures 5B,C show the top 150 differentially expressed genes in ULPs and NLPs. Among these differentially expressed 
A

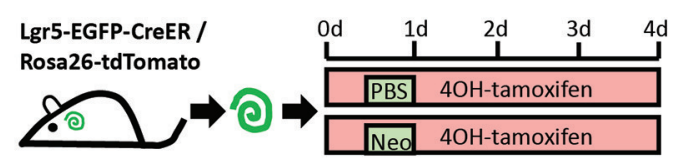

B

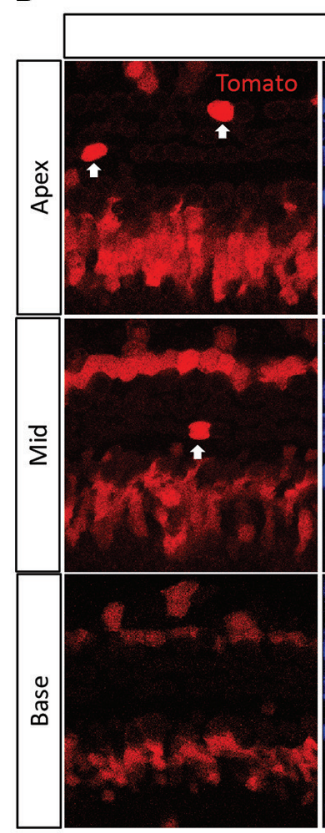

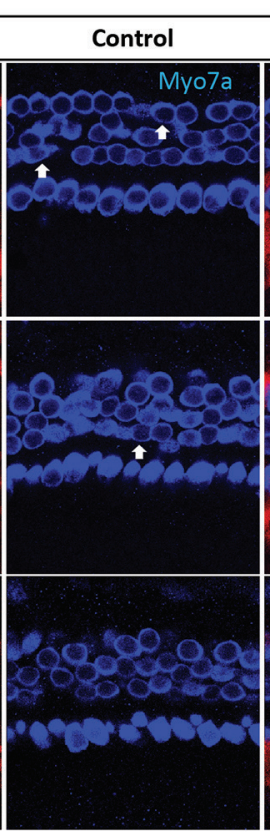
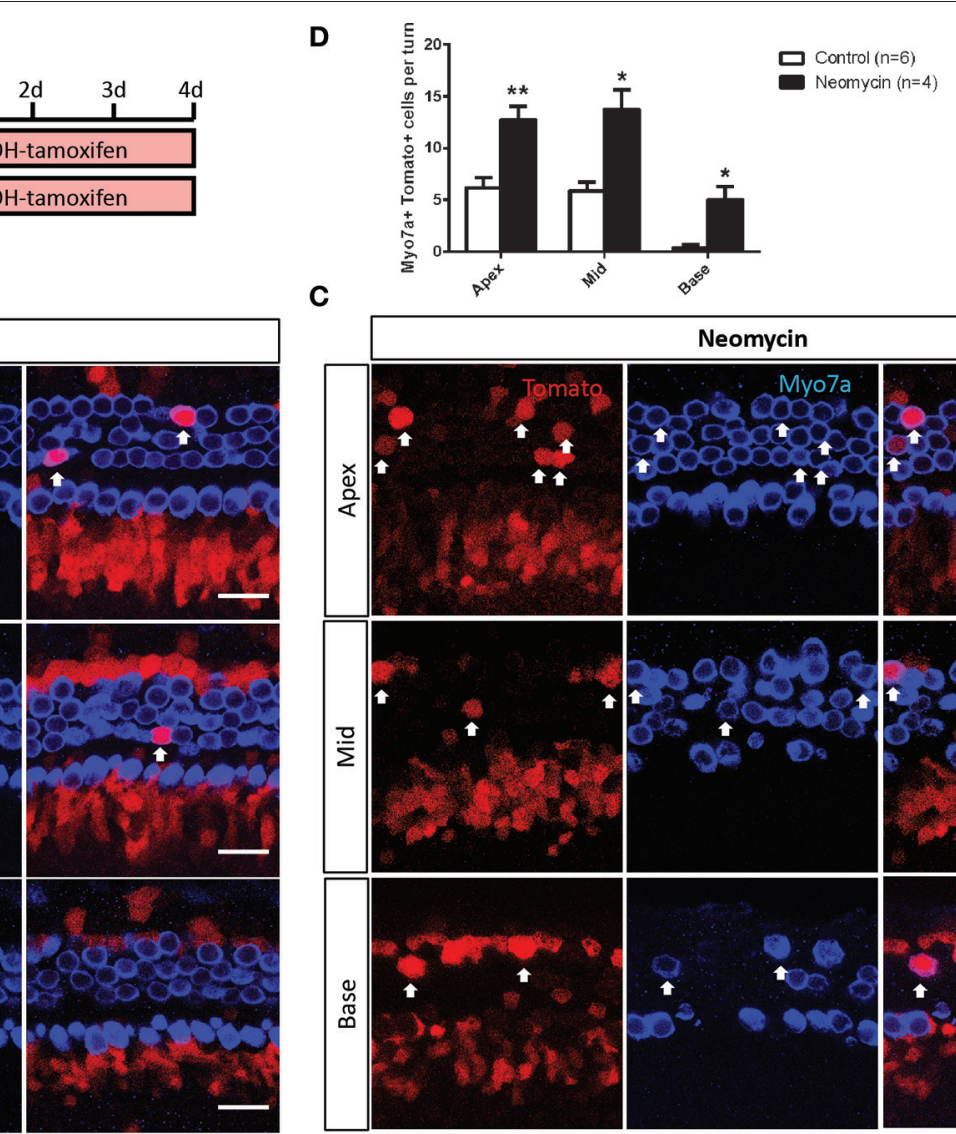

C
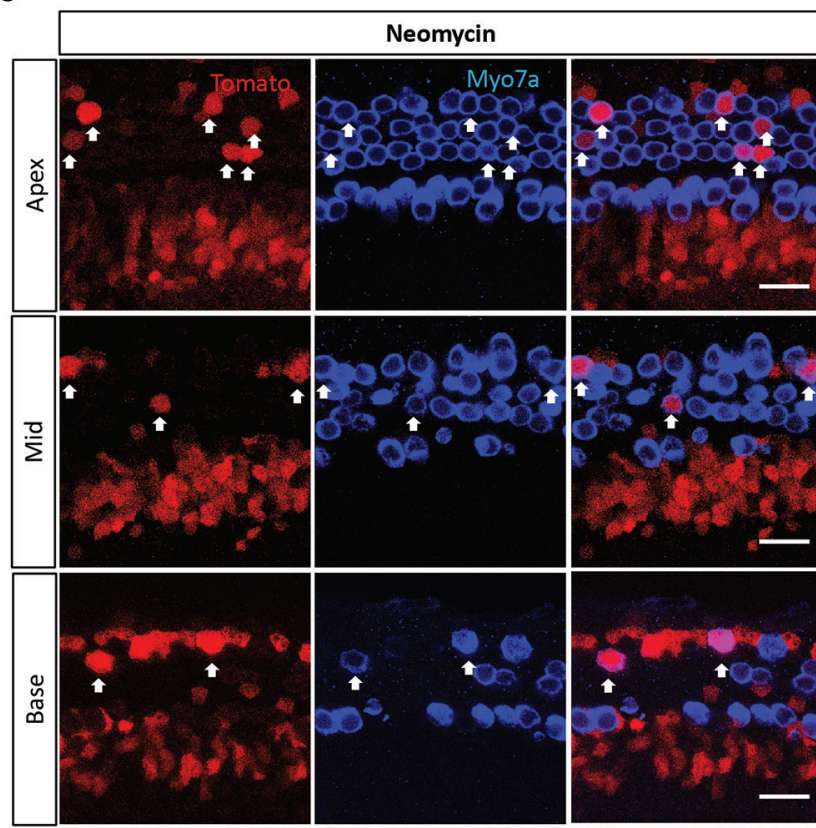

FIGURE 1 | In vitro lineage tracing of Lgr5+ cells in the neomycin-treated and untreated cochleae of postnatal mice. (A) $4 \mathrm{OH}$-tamoxifen was added to the culture medium of P1 Lgr5-EGFP-creER/Rosa26-tdTomato mouse cochleae throughout the entire culture period. Neomycin was added at $12 \mathrm{~h}$ after the start of the culture and was allowed to incubate for $12 \mathrm{~h}$, and the same amount of PBS was added to the untreated cochlear culture medium for the same amount of time. The cochleae were examined after 4 days of culture. (B,C) Images of the neomycin-treated and untreated cochleae show that tdTomato+/Myo7a+ cells were found in the outer hair cell subset (arrow) in the apical, middle, and basal turns. (D) The cochleae were divided into three equal parts by length (apex, middle, and base), and all of the tdTomato+/Myo7a+ cells in each turn of the neomycin-treated cochleae and untreated cochleae were counted and statistically analyzed. ${ }^{*} p<0.05,{ }^{* *} p<0.01, n$ is shown in parentheses. Scale bars are $20 \mu \mathrm{m}$ in $\mathbf{( B , C )}$.

genes, the functions of some genes have been reported previously. Fgfr3 (Bermingham-McDonogh et al., 2001; White et al., 2012), Egfr (Saleem and Siddiqui, 2015), Frem2 (Nadol et al., 2015), Alms1 (Oshima et al., 2007b; Jagger et al., 2011), and Lif (Marzella et al., 1999; Su et al., 2015) were upregulated in NLPs, while Hes1, Hes5 (Zheng et al., 2000; Zine et al., 2001; Li et al., 2008; Murata et al., 2009; Abdolazimi et al., 2016), Hey1 (Tateya et al., 2011; Korrapati et al., 2013; Benito-Gonzalez and Doetzlhofer, 2014; Petrovic et al., 2015), HeyL (Kamaid et al., 2010), Id1, Id2, and Id3 (Ozeki et al., 2005; Jones et al., 2006; Laine et al., 2010) were downregulated in NLPs. We did not find any functional reports for the other differentially expressed genes in the cochleae, and these should be further studied in the future.

\section{Cell Cycle Analysis}

Cells in the postnatal mammalian cochlea have exited the cell cycle, and they have very limited capacity for proliferation. In order to promote mitotic $\mathrm{HC}$ regeneration, it is important to induce $\mathrm{HC}$ progenitors to re-enter the cell cycle and to mitotically regenerate HCs. In the present study, we have demonstrated that neomycin injury could induce the proliferation of Lgr5+ progenitors; however, the detailed mechanism behind this proliferative ability remains unclear. It has been reported that some of the cell cycle genes play important roles in the cochlea. To identify the possible genes regulating the cell cycling of Lgr5+ progenitors, we examined the expression levels of cell cycle genes in NLPs and ULPs. We found that $C d k n 1 a, M d m 2$, Tfdp1, and Wee1 were significantly upregulated in NLPs and that Ccne2, Gadd45g, Nek2, Sfn, and Stmn1 were significantly downregulated in ULPs (Figure 6A). Real-time PCR was also performed to confirm the RNA-seq results, and these two results were consistent (Figure 6D). Only the roles of Cdkn1a (Laine et al., 2007; Laos et al., 2017) and Mdm2 (Mahmoodian Sani et al., 2016) in the inner ear have been described, and there are no reports of the roles of the other cell cycle genes we identified in ULPs and NLPs. 
A

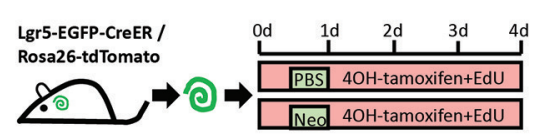

C

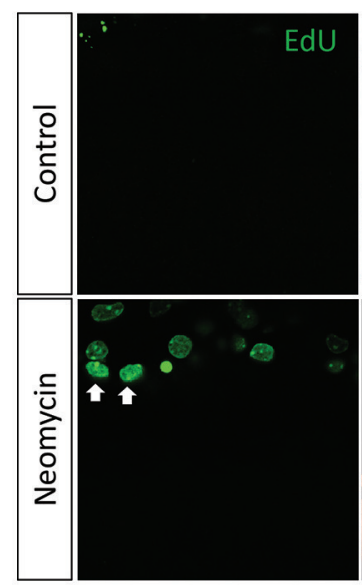

B

\begin{tabular}{|c|c|c|c|}
\hline $\begin{array}{c}\text { EdU+ Tomato+ } \\
\text { per cochlea }\end{array}$ & $\begin{array}{c}\text { Control } \\
(\mathbf{n}=5)\end{array}$ & $\begin{array}{c}\text { Neomycin } \\
(\mathbf{n}=\mathbf{7})\end{array}$ & P-value \\
\hline D3 & 0.0 & 0.7 & 0.093 \\
\hline PC & 0.0 & 0.0 & N/A \\
\hline IPC & 0.0 & 0.0 & N/A \\
\hline GER & 0.0 & 0.0 & N/A \\
\hline
\end{tabular}
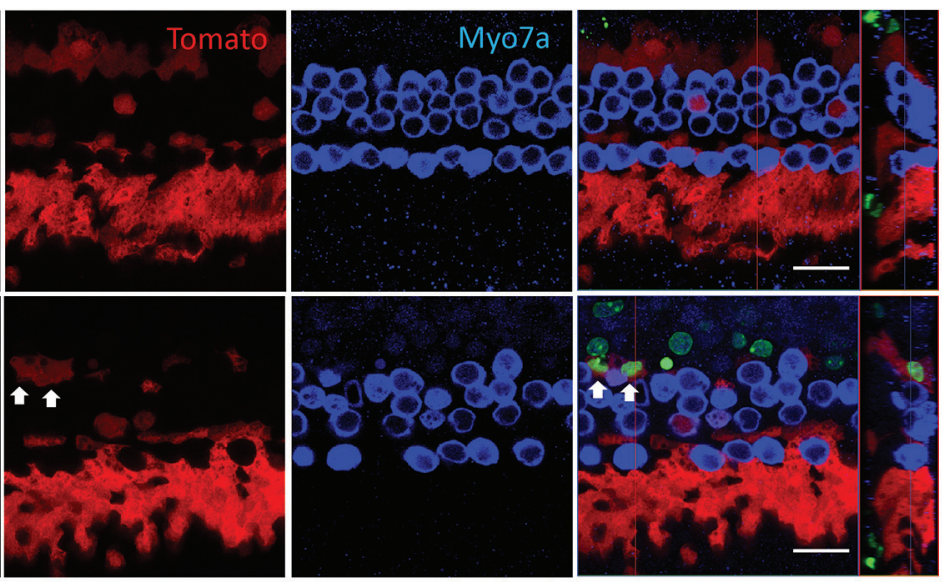

FIGURE 2 | EdU labeling measures the proliferation of Lgr5+ cells in the neomycin-treated and untreated cochleae of postnatal mice. (A) $4 \mathrm{OH}$-tamoxifen and EdU were added to the culture medium of P1 Lgr5-EGFP-creER/Rosa26-tdTomato mouse cochleae throughout the culture period. Neomycin was added at $12 \mathrm{~h}$ after the start of the culture and was allowed to incubate for $12 \mathrm{~h}$, and the same amount of PBS was added to the untreated cochleae culture medium for the same amount of time. The cochleae were examined after 4 days of culture. (B) All of the tdTomato+/EdU+ cells found in the neomycin-treated cochleae and the untreated cochleae were counted and statistically analyzed. The $p=0.093, n$ is shown in parentheses. D3, the third-row Deiters' cells; PC, inner pillar cells; IPC, inner phalangeal cells; GER, the lateral greater epithelial ridge. (C) Images of the neomycin-treated and untreated cochleae show that tdTomato+/EdU+ cells were found in the neomycin-treated cochleae (arrows). Scale bars are $20 \mu \mathrm{m}$ in (B).

\section{Transcription Factor Analysis}

Transcription factors (TFs) are able to bind to enhancer or promoter regions of their downstream target genes and control their expression levels. There are many TFs involved in inner ear development and HC regeneration. In the present study, we have demonstrated that NLPs have significantly greater $\mathrm{HC}$ regeneration capacity compared to ULPs (Figure $1, p<0.05$, $n \geqq 4$ ). However, the roles of a large number of TFs in the inner ear and in $\mathrm{HC}$ regeneration are unknown. To determine the TFs that might be involved in HC regeneration from Lgr5+ progenitors, we compared the expression levels of TFs in the mouse genome between NLPs and ULPs. Figure 6B shows the 88 significantly differentially expressed TFs in NLPs and ULPs (fold change $>2, p<0.05$ ). Some of the TFs that were downregulated in NLPs, including Hes1, Hes5 (Zheng et al., 2000; Li et al., 2008; Murata et al., 2009; Abdolazimi et al., 2016), Hey1 (Tateya et al., 2011; Korrapati et al., 2013; Benito-Gonzalez and Doetzlhofer, 2014; Petrovic et al., 2015), HeyL (Kamaid et al., 2010), Id1, Id2, and Id3 (Ozeki et al., 2005; Jones et al., 2006; Laine et al., 2010), have been reported to play roles in negatively regulating $\mathrm{HC}$ fate and patterning regulation during inner ear development (Figure 6B). Real-time PCR was also performed to confirm the RNA-seq results, and these two results were consistent (Figure 6E). However, a significant number of the differentially expressed TFs have not been characterized in the inner ear before and need to be further studied in the future.

\section{MicroRNA Analysis}

MicroRNAs (miRNAs) are untranslated RNAs that control gene expression by binding to target mRNAs. A few miRNAs have been reported to play important roles in HC protection and $\mathrm{HC}$ regeneration (Jen et al., 1997; Li et al., 2010; Wang et al., 2010; Patel and $\mathrm{Hu}, 2012)$. We found that 149 miRNAs were uniquely expressed in ULPs, 151 miRNAs were uniquely expressed in NLPs, and 59 miRNAs were expressed in both ULPs and NLPs. Among these miRNAs, eight miRNAs were significantly differentially expressed in NLPs and ULPs $(p<0.05$, fold change $>2$; Figure 6C). Mir466i was upregulated in NLPs, while Mir7007, mmu-mir-703, Mir107, Mir361, Mir6918, Mir6982, and Mir3099 were downregulated in NLPs. These miRNAs have not been characterized in the inner ear and need to be further studied in the future.

\section{Signaling Pathway Analysis}

A few signaling pathways have been shown to be involved in inner ear development and $\mathrm{HC}$ regeneration. To determine which pathways might be involved in regulating $\mathrm{HC}$ regeneration from Lgr5+ progenitors, we compared the expression of genes involved in these pathways between the NLPs and ULPs. The most significantly different expression was in genes involved in the Notch and TGF $\beta$ pathways. Among the Notch signaling genes examined here, Hes1, Hes5, Heyl, HeyL, and Notch4 were all significantly downregulated in NLPs compared to ULPs 

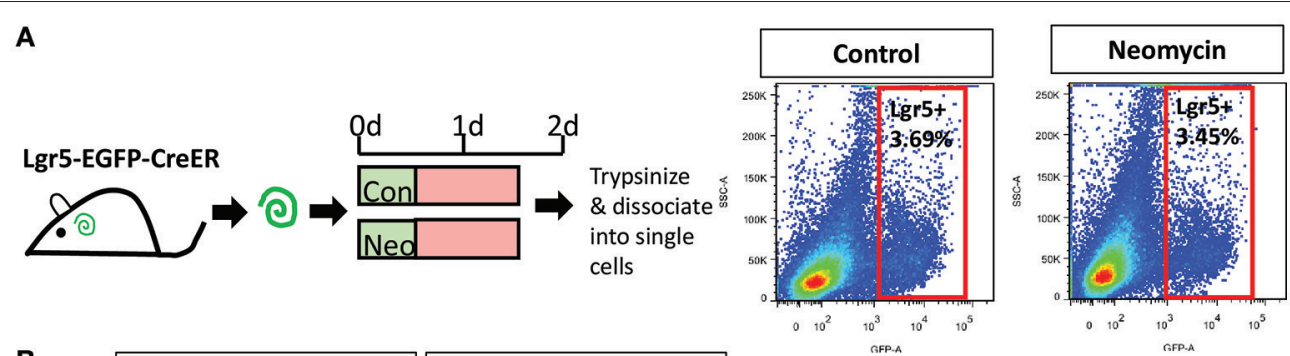

B
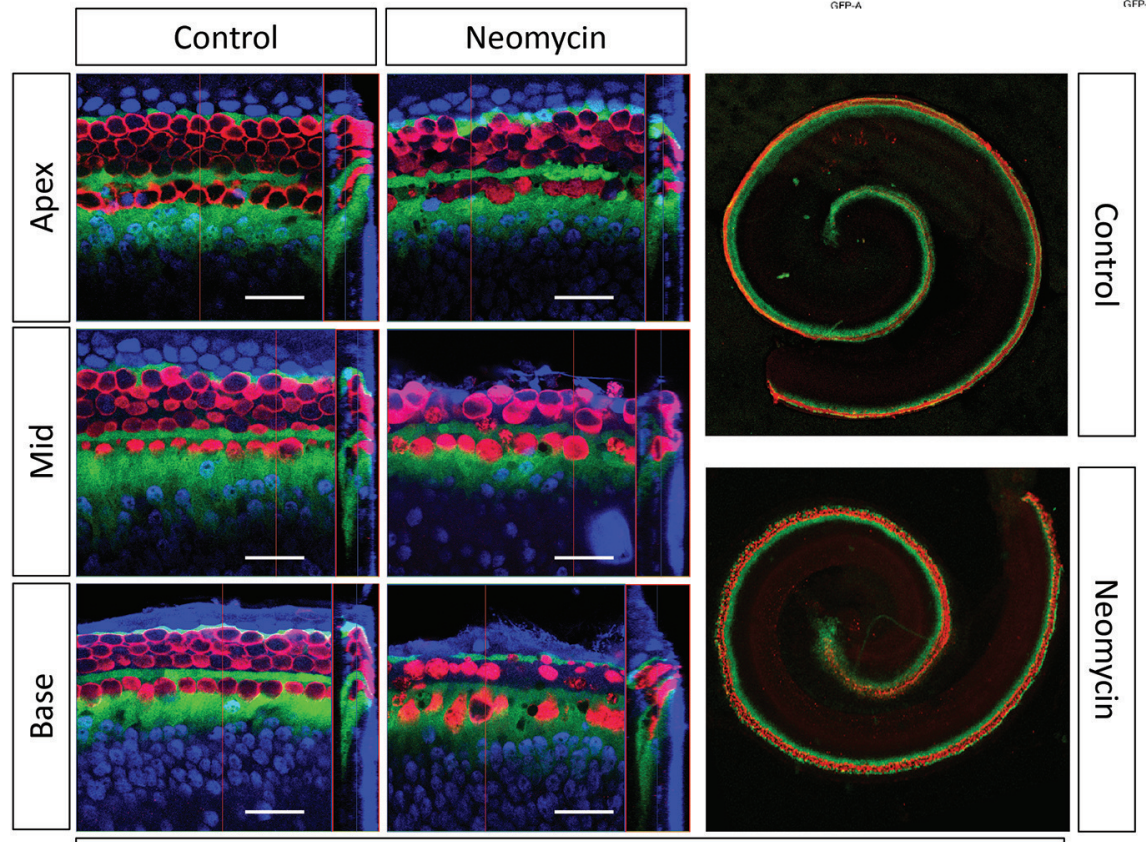

EGFP / Myo7a / Sox2

$\circ$

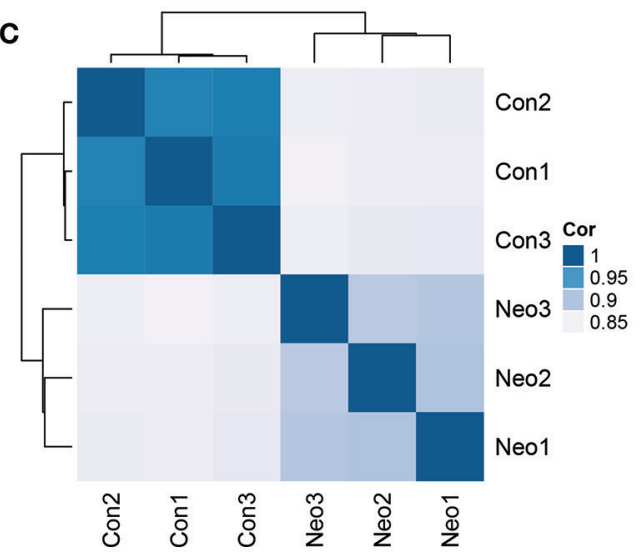

D

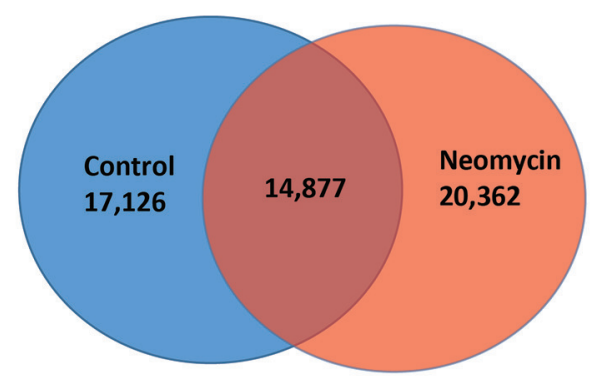

FIGURE 3 | FACS sorting of Lgr5+ cells in the neomycin-treated and untreated cochleae of postnatal mice. (A,B) Neomycin was added for $12 \mathrm{~h}$ to the P1 Lgr5-EGFP-creER/Rosa26-tdTomato mouse cochleae, and the same amount of PBS was added to the untreated cochlear culture medium for the same amount of time. After a $24 \mathrm{~h}$ recovery period, the cochleae were trypsinized and dissociated into single cells for FACS sorting. (C) PCA analysis for all three replicates of NLPS (Neo1, Neo2, Neo3) and ULPs (Con1, Con2, Con3). (D) Venn diagram showing the number of genes expressed in NLPS (Neomycin) and ULPs (Control).

(Figure 7A). Among the TGF $\beta$ pathway genes, Tfdp1 and Bmpr2 were upregulated, while $I d 1, I d 2$, and $I d 3$ were downregulated in NLPs (Figure 7C). Among the Wnt pathway genes, Wnt7a and $F z d 7$ were upregulated, while Sfrp1, Ctnnbip1, Mapk10, and Dkk2 were downregulated in NLPs (Figure 7B). Among the Hippo pathway genes, Bmpr2, Wnt7a, and Fzd7 were upregulated, while $I d 1, I d 2$, and $I d 3$ were downregulated in NLPs (Figure 7D). Real-time PCR was also performed to confirm the RNA-seq 


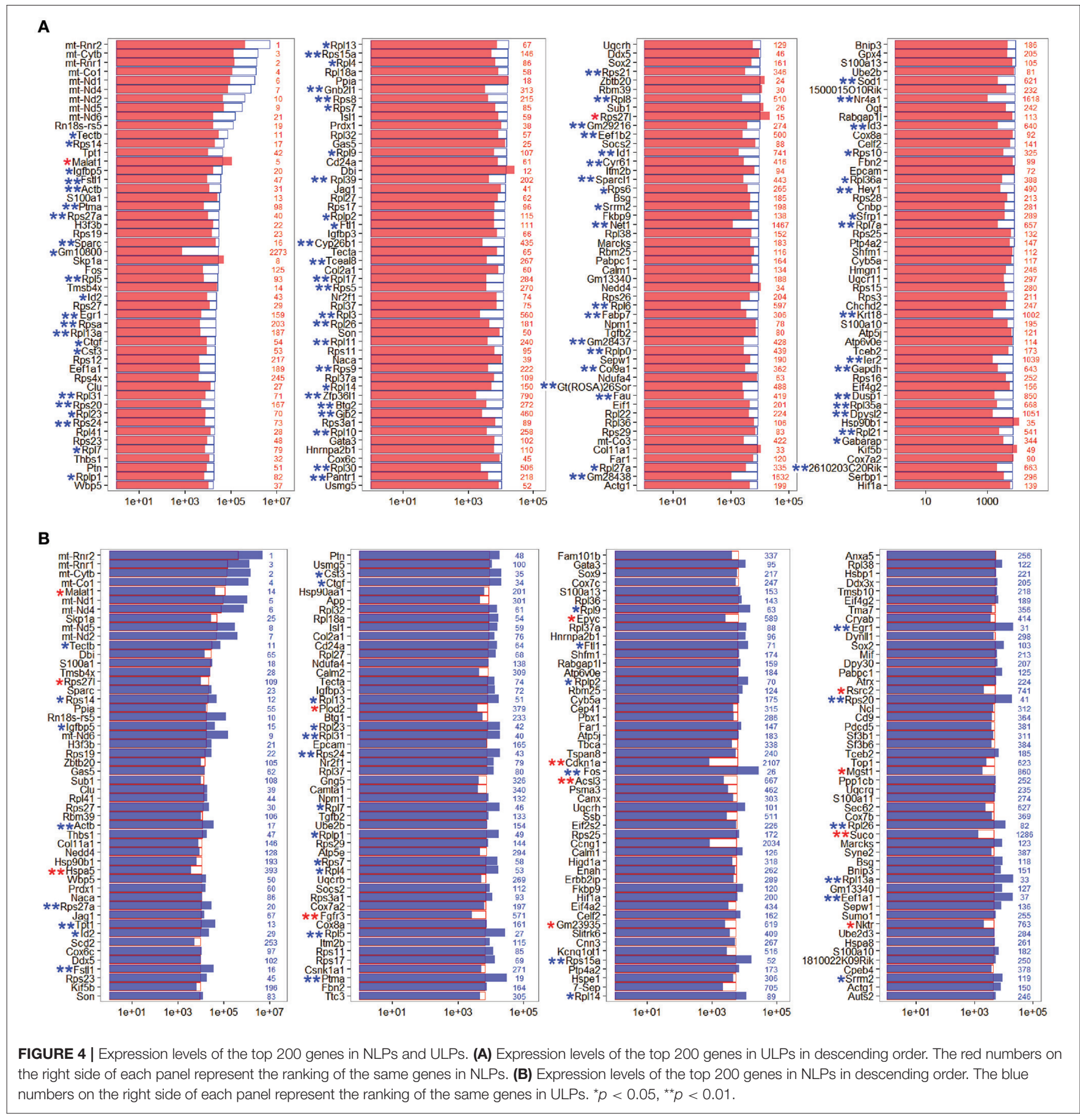

results, and these two results were consistent (Figure $7 \mathbf{E}$ ). The differential expression of genes in the Notch, TGF $\beta$, Wnt, and Hippo pathways suggests that these pathways might be involved in neomycin-induced HC regeneration. Some studies have shown that the Notch and Wnt pathways regulate the development of inner ear progenitor cells (Chai et al., 2012; Kelly et al., 2012). Thus, although the TGF $\beta$ and Hippo pathways are not well-studied they are probably the pathways that regulate $\mathrm{HC}$ regeneration.

\section{Gene Ontology and Network Analysis of the Genes That Are Differentially Expressed in Lgr5+ Cells from Neomycin-Damaged and Undamaged Cochleae}

To view the interactions and connections of genes that are differentially expressed in NLPs and ULPs, we constructed a STRING protein-protein interaction network for the significantly differentially expressed genes (fold change $>2.0, p<0.05$ ) with 


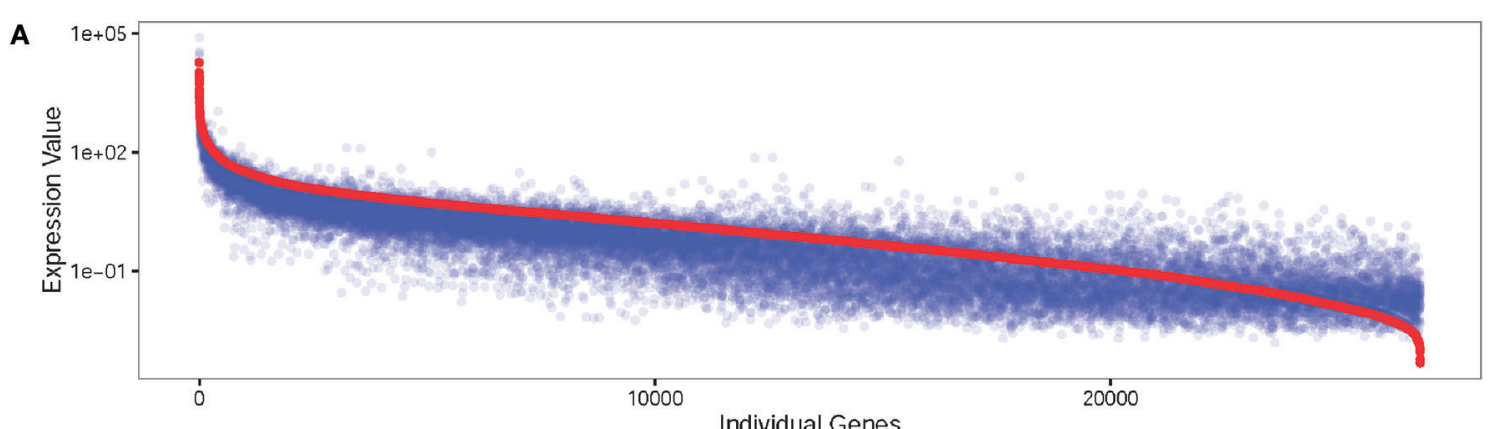

B

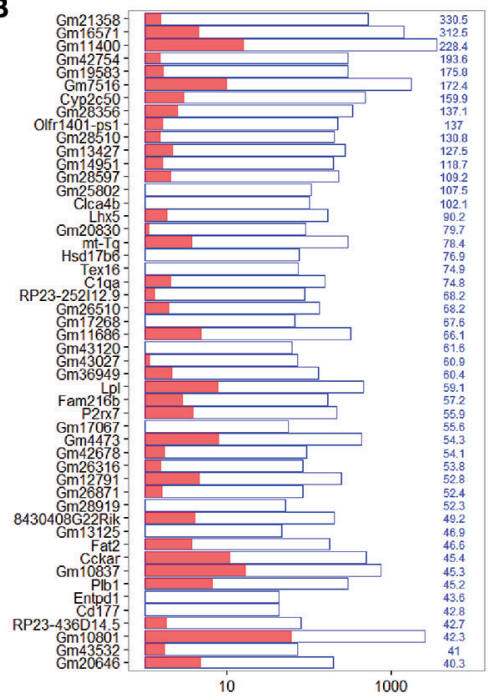

C

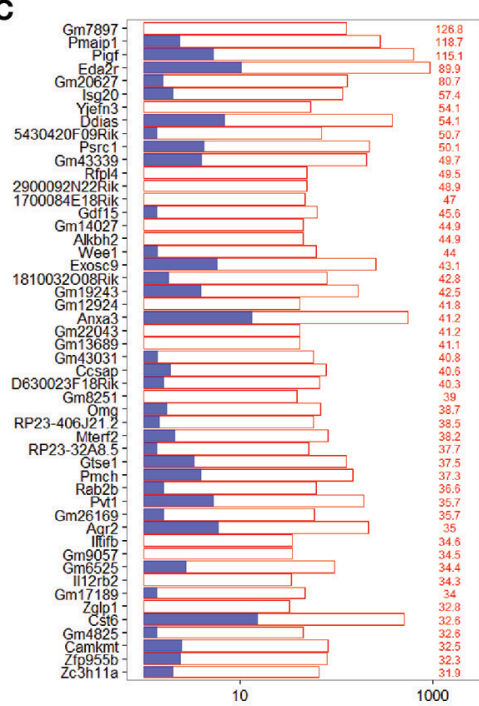

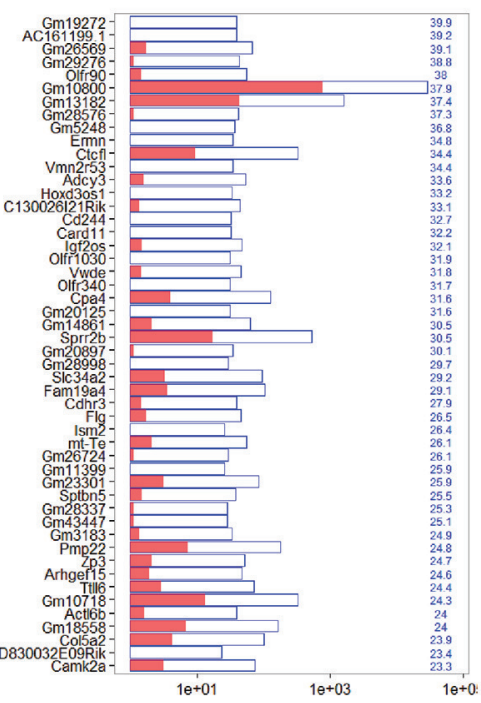
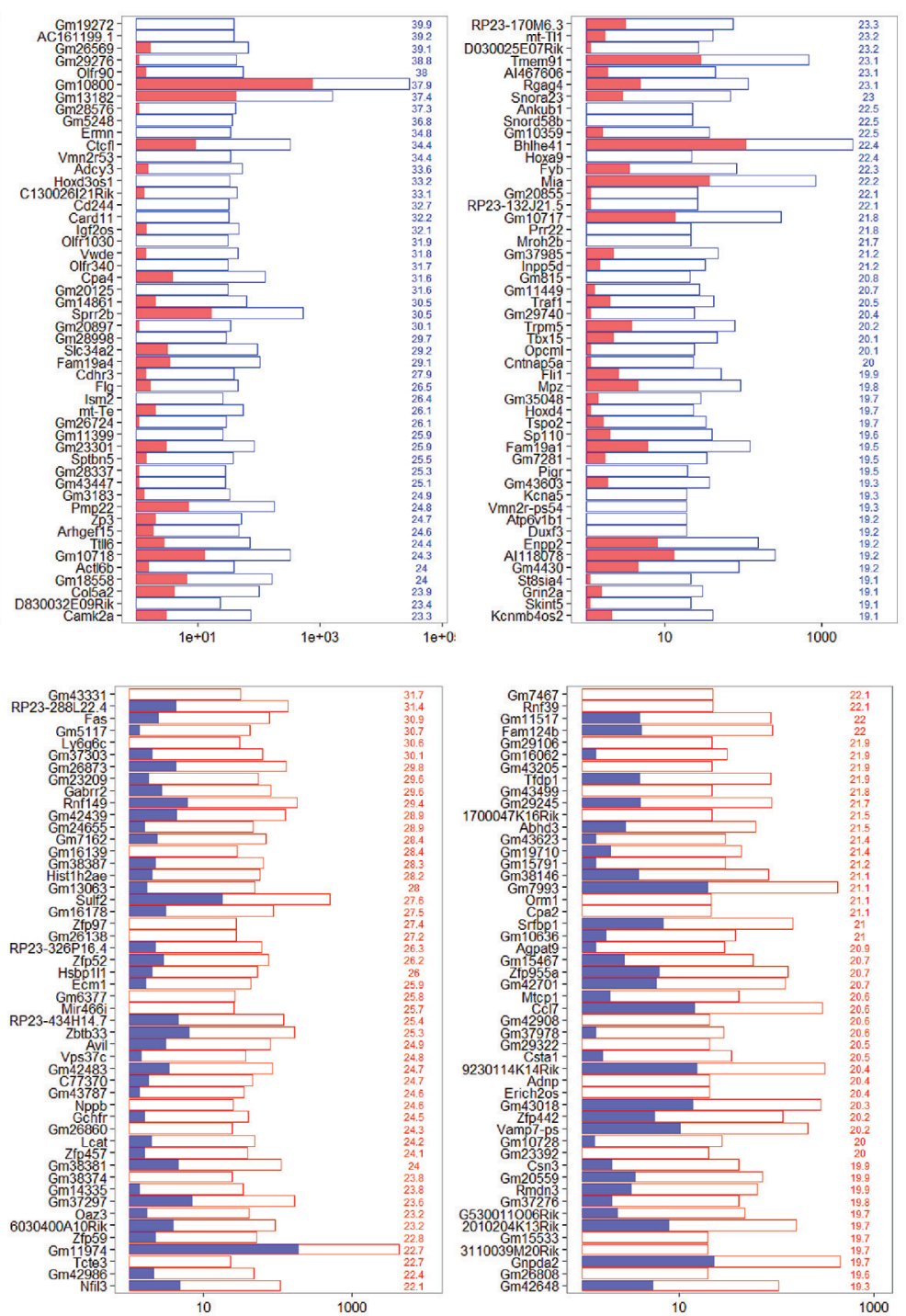

FIGURE 5 | Differentially expressed genes in NLPS and ULPS. (A) All differentially expressed genes in NLPs and ULPs. The red line represents the expression level of transcripts from NLPS, and each blue dot represents the expression level of the same transcript from ULPS. (B) The 150 most differentially expressed genes in ULPS. The blue numbers on the right side of each panel represent the gene expression fold change in ULPs compared to NLPs. (C) The 150 most differentially expressed genes in NLPs. The red numbers on the right side of each panel represent the gene expression fold change in NLPs compared to ULPS.

the functional categories in the gene ontology (GO) analysis (DAVID; Figure 8B). This comprehensive analysis revealed a complex gene network that might regulate $\mathrm{HC}$ regeneration. We also applied GO analysis to genes with altered expression levels in NLPs (fold change $>2.0, p<0.05$; Figure 8A). The genes with altered expression in NLPs were highly enriched in functional 

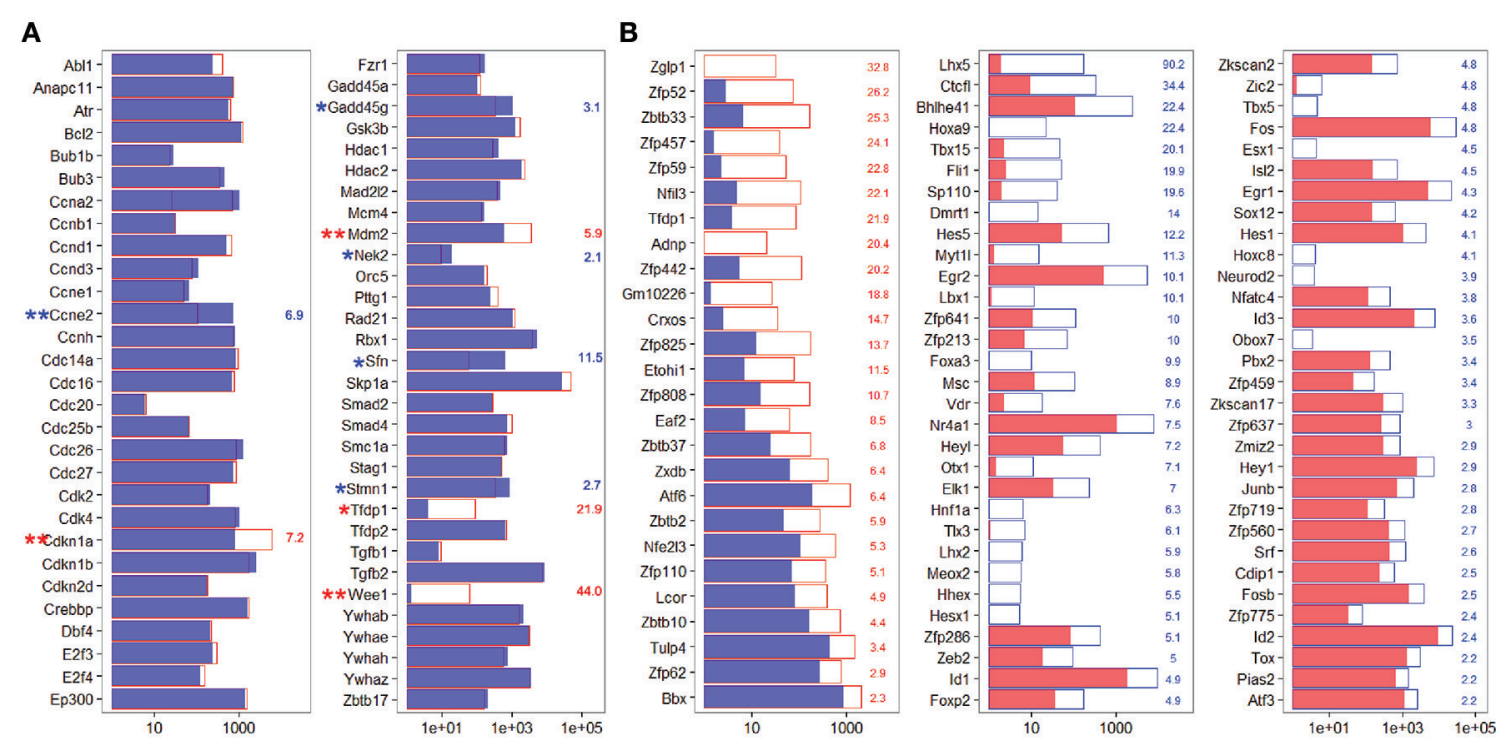

C

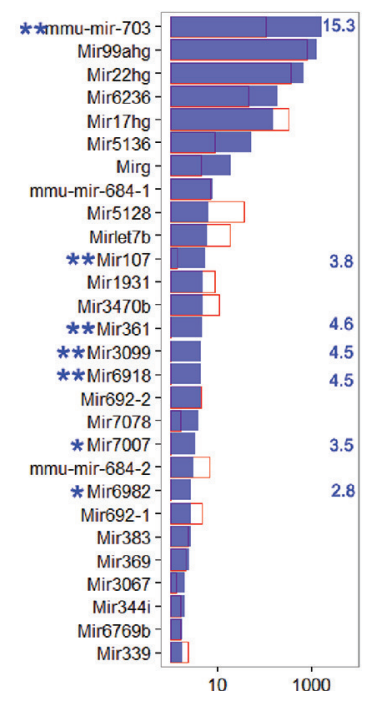

D

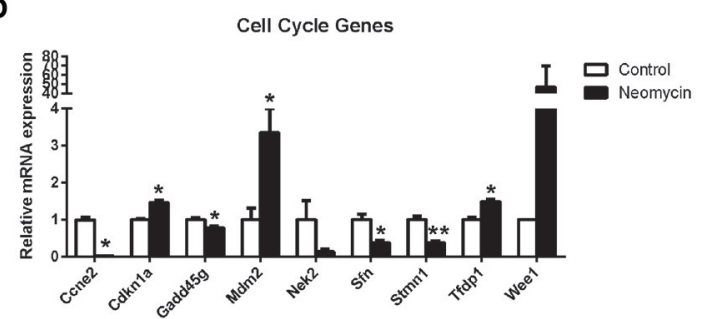

E

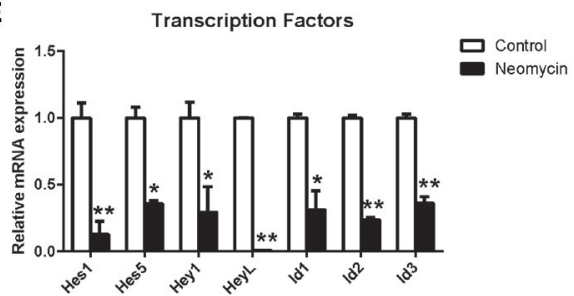

FIGURE 6 | Expression of cell cycle-related genes, TFs, and miRNAs. (A) Expression levels of 60 genes that are involved in cell cycle regulation. (B) Fold change expression levels of differentially expressed transcription factors in descending order. (C) Expression levels of 57 microRNAs expressed in the cochlea. In all three panels, the red and blue numbers separately represent the fold change in upregulated and downregulated gene expression in NLPs compared to ULPS. ${ }^{*} p<0.05$, ${ }^{* *} p<0.01$. (D) Real-time PCR analysis of the cell cycle genes. (E) Real-time PCR analysis of the TFs reported in the inner ear. ${ }^{*} p<0.05,{ }^{* *} p<0.01 . n=3$.

categories such as auditory receptor cell fate determination, neuron fate determination, signaling, and extracellular matrix formation and maintenance.

\section{DISCUSSION}

The Lgr5+ cells of the cochlea are reported to be an enriched population of $\mathrm{HC}$ progenitors that have high potential for HC regeneration. Previous studies have shown that Lgr5+ progenitors regenerate more HCs upon damage in vitro and in vivo, but the detailed mechanisms behind NLP HC regeneration and the gene expression profile differences between NLPs and
ULPs are not well-understood. Here, we found that NLPs show much greater capacity for HC regeneration than ULPs and that NLPs have slightly greater proliferation than ULPs. We carried out RNA-seq experiments to analyse the detailed gene expression profile of NLPs and ULPs. We first analyzed the top 200 most abundant genes and top 150 most differentially expressed genes in NLPs and ULPs, and we found 9 cell cycle genes, 88 TFs, and 16 signaling pathway genes that were differentially expressed in NLPs and ULPs. Some of the differentially expressed genes have been reported to be involved in inner ear development and HC regeneration in neonatal mice. However, many of the other genes, which might be potential targets regulating HC regeneration, 


\section{A Notch}

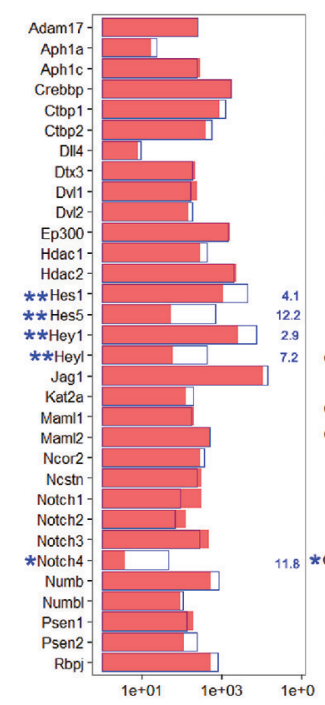

\section{B Wnt}

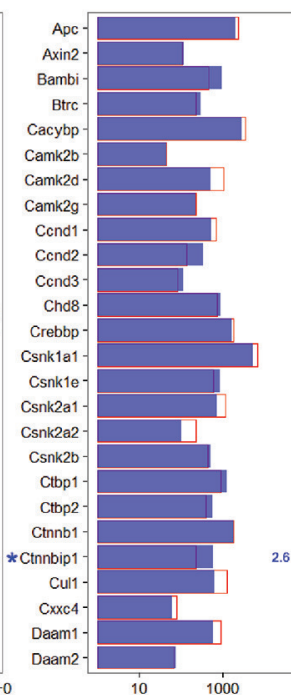

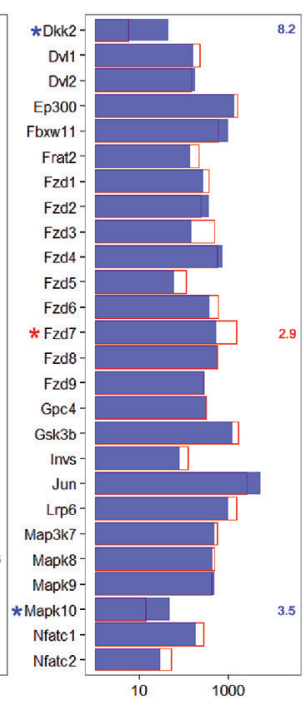

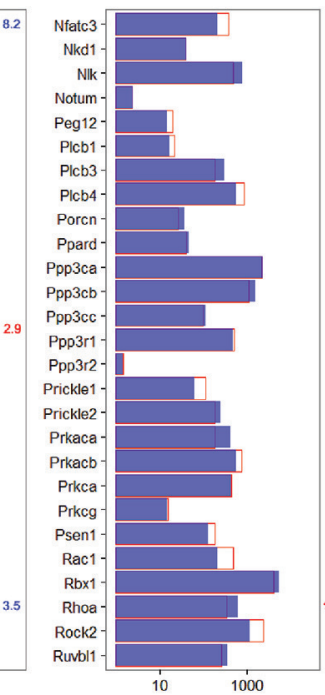

\section{TGF $\beta$}

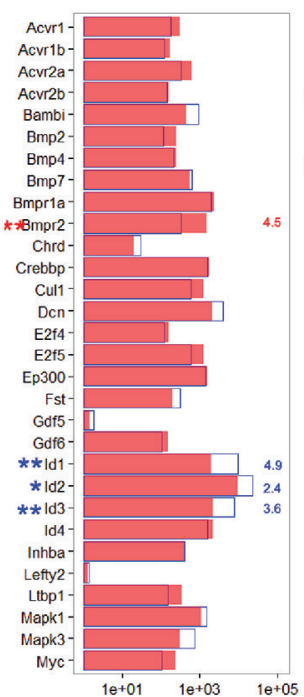

\section{Hippo}

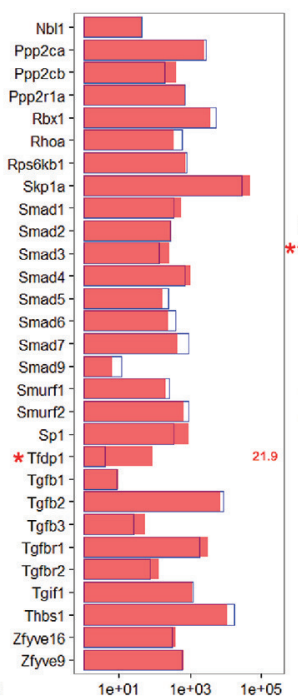

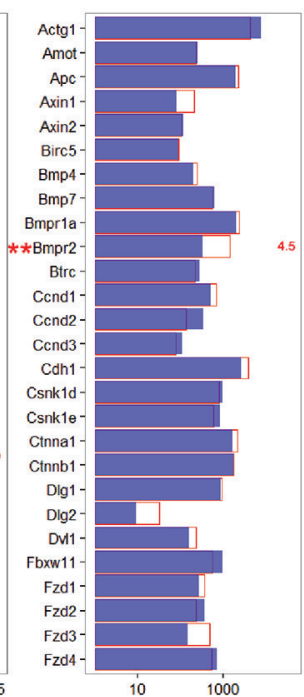
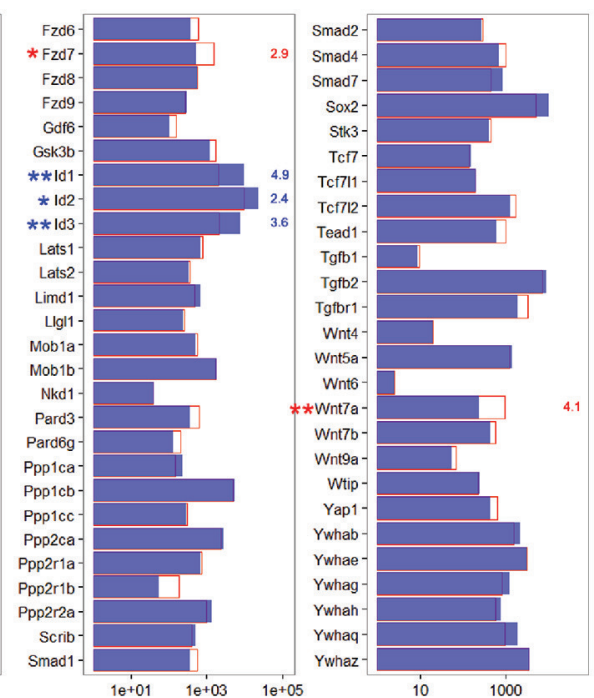

E

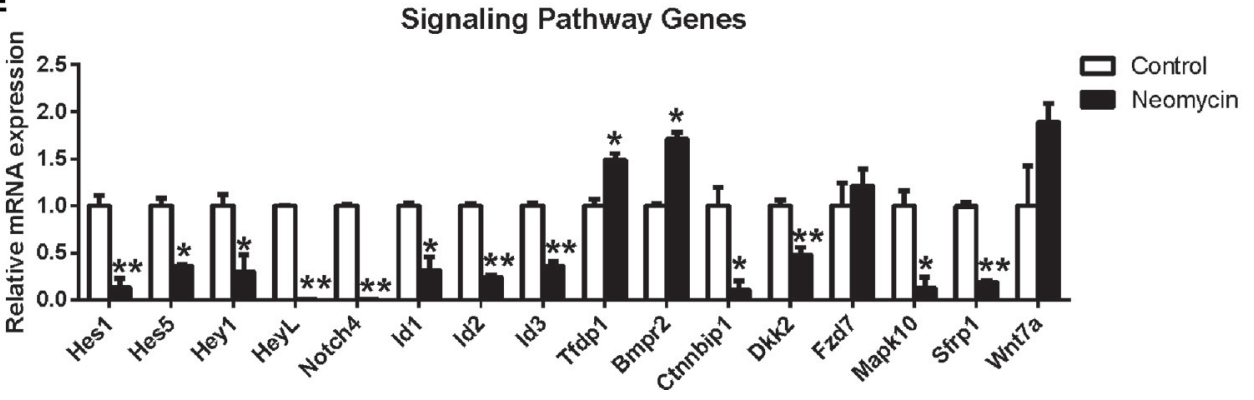

FIGURE 7 | Expression of genes in the Notch, Wnt, TGF $\beta$, and Hippo signaling pathways. (A) Expression levels of 32 genes that are important for the Notch signaling pathway. (B) Expression levels of 105 genes that are important for the Wnt signaling pathway. (C) Expression levels of 59 genes that are important for the TGF $\beta$ signaling pathway. (D) Expression levels of 80 genes that are important for the Hippo signaling pathway. In all four panels, the red and blue numbers separately represent the fold change in upregulated and downregulated gene expression in NLPs compared to ULPS. ${ }^{*} p<0.05$, ${ }^{* *} p<0.01$. (E) Real-time PCR analysis of the signaling pathway genes. ${ }^{\star} p<0.05,{ }^{* *} p<0.01 . n=3$. 
A

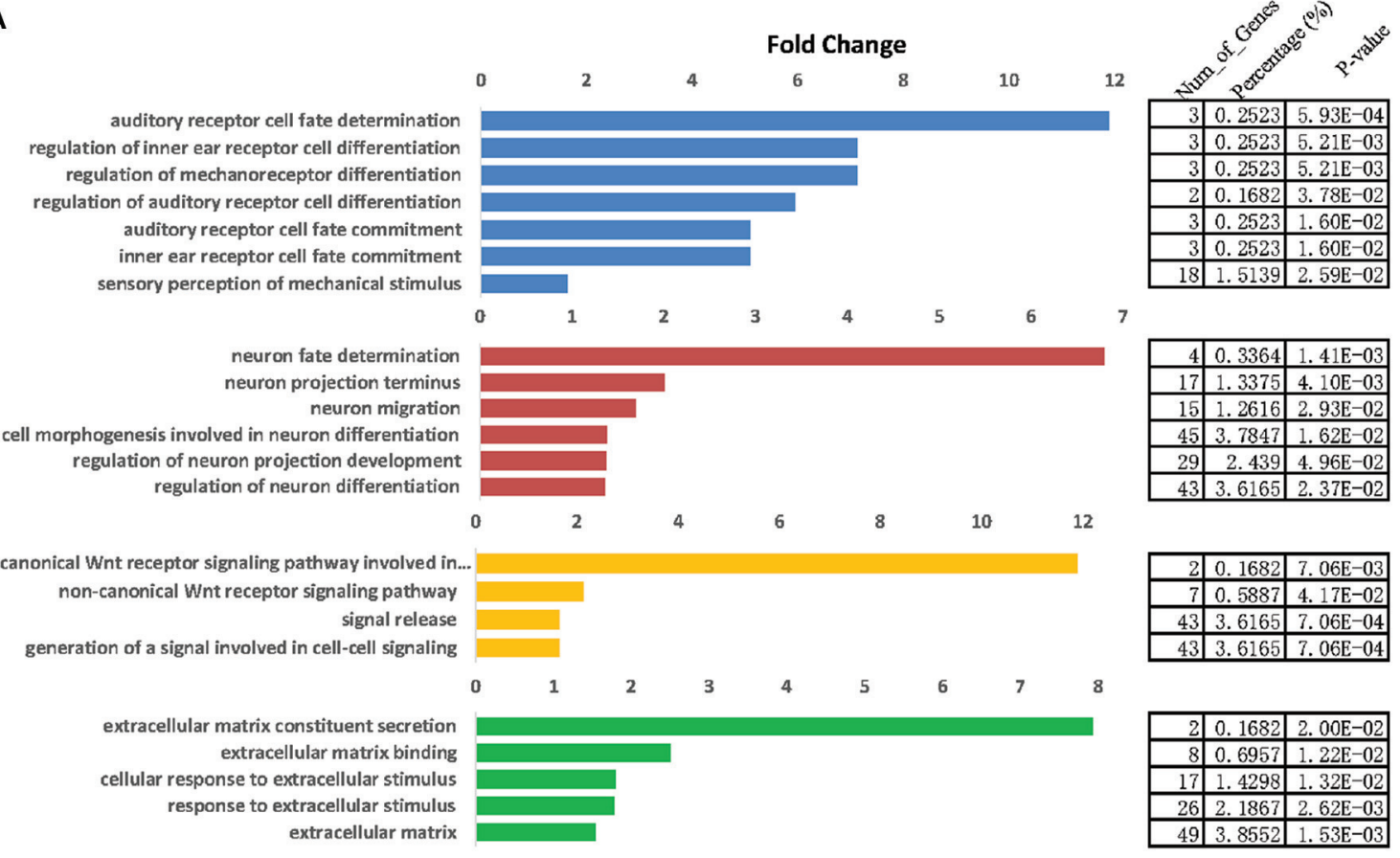

B

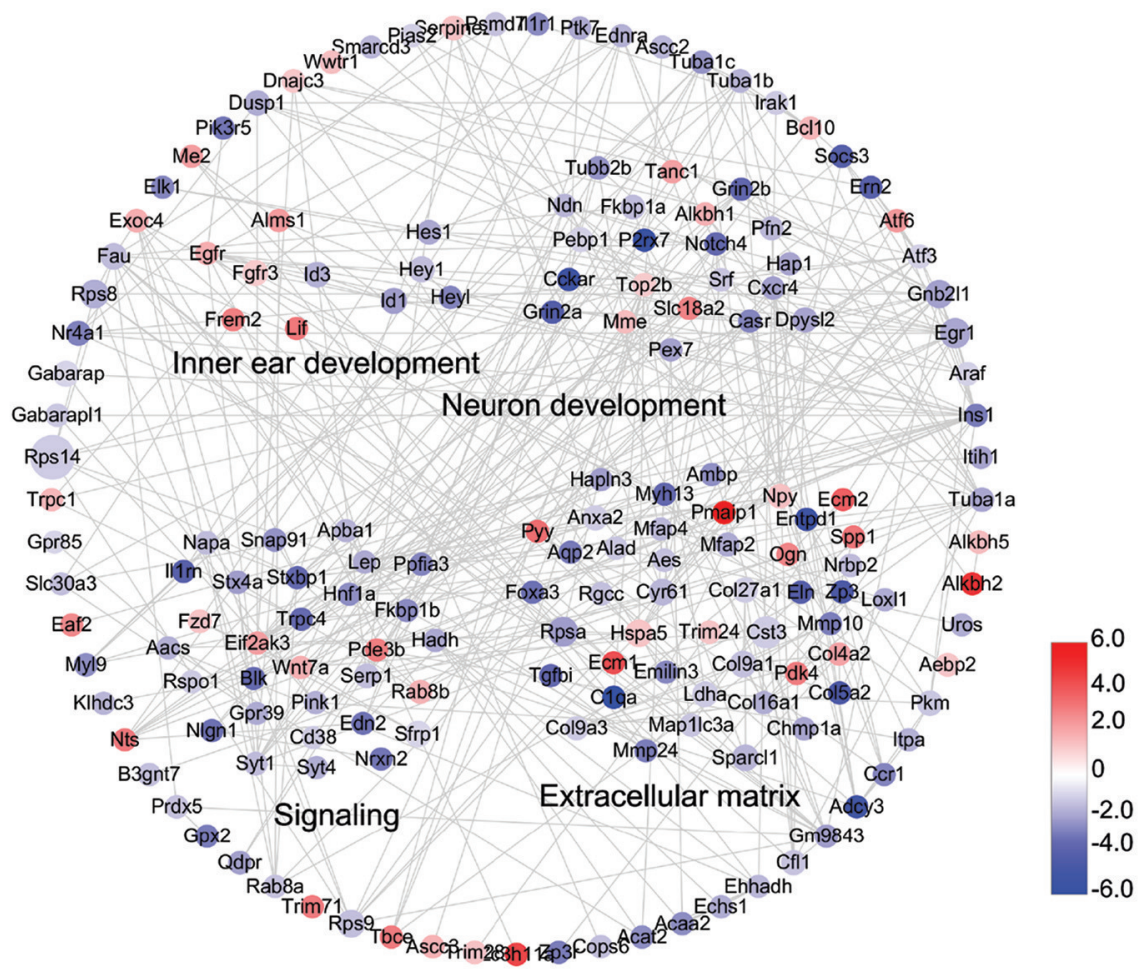

FIGURE 8 | Gene ontology (GO) and network analysis of the differentially expressed genes in NLPs and ULPs. (A) GO analysis of differentially expressed genes in NLPS and ULPS. (B) STRING protein-protein interaction analysis of genes that are upregulated (red) and downregulated (blue) in NLPS. The gray lines indicate protein-protein interactions in the STRING database. The DAVID GO annotation was used to cluster the genes according to biological function. 
TABLE 1 | Real-time PCR primers.

\begin{tabular}{|c|c|c|c|}
\hline Gene symbol & Primers $\left(5^{\prime}-3^{\prime}\right)$ & Gene symbol & Primers $\left(5^{\prime}-3^{\prime}\right)$ \\
\hline Hes1-F & CCAGCCAGTGTCAACACGA & Nek2-F & TTCCATCCTCAGCCATGAAGA \\
\hline Hes1-R & AATGCCGGGAGCTATCTITCT & Nek2-R & CCTGCACTTGGACTTGGCAA \\
\hline Hes5-F & AGTCCCAAGGAGAAAAACCGA & Sfn-F & GTGTGTGCGACACCGTACT \\
\hline Hes5-R & GCTGTGTITCAGGTAGCTGAC & Sfn-R & CTCGGCTAGGTAGCGGTAG \\
\hline Hey1-F & GCGCGGACGAGAATGGAAA & Stmn1-F & TCTGTCCCCGATITCCCCC \\
\hline Hey1-R & TCAGGTGATCCACAGTCATCTG & Stmn1-R & AGCTGCTTCAAGACTTCCGC \\
\hline HeyL-F & CAGCCCTTCGCAGATGCAA & Notch4-F & CTCTTGCCACTCAATTTCCCT \\
\hline HeyL-R & CCAATCGTCGCAATTCAGAAAG & Notch4-R & TTGCAGAGTTGGGTATCCCTG \\
\hline Id1-F & CCTAGCTGTTCGCTGAAGGC & Bmpr2-F & TTGGGATAGGTGAGAGTCGAAT \\
\hline Id1-R & CTCCGACAGACCAAGTACCAC & Bmpr2-R & TGTITCACAAGATTGATGTCCCC \\
\hline Id2-F & ATGAAAGCCTTCAGTCCGGTG & Wnt7a-F & GGCTTCTCTTCGGTGGTAGC \\
\hline Id2-R & AGCAGACTCATCGGGTCGT & Wnt7a-R & TGAAACTGACACTCGTCCAGG \\
\hline Id3-F & GACGACATGAACCACTGCTAC & Fzd7-F & GCCACACGAACCAAGAGGAC \\
\hline Id3-R & CCTGGCTAAGCTGAGTGCC & Fzd7-R & CGGGTGCGTACATAGAGCATAA \\
\hline Cdkn1a-F & CCTGGTGATGTCCGACCTG & Sfrp1-F & CAACGTGGGCTACAAGAAGAT \\
\hline Cdkn1a-R & CCATGAGCGCATCGCAATC & Sfrp1-R & GGCCAGTAGAAGCCGAAGAAC \\
\hline Mdm2-F & TGTCTGTGTCTACCGAGGGTG & Ctnnbip1-F & GCCACAGCACTCCATCGAC \\
\hline Mdm2-R & TCCAACGGACTITAACAACTTCA & Ctnnbip1-R & GTCTCCGATCTGGAAAACGC \\
\hline Tfdp1-F & TTGAAGCCAACGGAGAACTAAAG & Mapk10-F & AAGCCAGGGATITGTTGTCTAAG \\
\hline Tfdp1-R & TGGACTGTCCGAAGGTIITG & Mapk10-R & GGATGGAGGGAGACTCTCACT \\
\hline Wee1-F & GTCGCCCGTCAAATCACCTT & Dkk2-F & CTGATGCGGGTCAAGGATTCA \\
\hline Wee1-R & GAGCCGGAATCAATAACTCGC & Dkk2-R & СTCСССТCСTAGAGAGGACTT \\
\hline Ccne2-F & ATGTCAAGACGCAGCCGTITA & Wwtr1-F & CATGGCGGAAAAAGATCCTCC \\
\hline Ccne2-R & GCTGATTCCTCCAGACAGTACA & Wwtr1-R & GTCGGTCACGTCATAGGACTG \\
\hline Gadd45g-F & GGGAAAGCACTGCACGAACT & Ppp2r2b-F & TGCCTTATATCTTCAGACCTCCA \\
\hline Gadd45g-R & AGCACGCAAAAGGTCACATTG & Ppp2r2b-R & AATGTCAGCTTCAGTATGGCAG \\
\hline
\end{tabular}

have not been well-studied and need to be further studied in the future.

\section{Differentially Expressed Genes in NLPs and ULPs}

We have demonstrated that NLPs are able to regenerate many more HCs than ULPs, which has been reported previously (Bramhall et al., 2014). To determine the detailed mechanisms behind this difference, we compared the expression levels of all of the transcripts in NLPs with those of ULPs. We identified 549 genes that were significantly upregulated and 1,817 genes that were significantly downregulated in the NLPs compared to the ULPs. The functions of some of the differentially expressed genes have been reported previously. Egfr governs the regenerative proliferation of auditory p75+ SCs in birds and mammals after HC damage (Saleem and Siddiqui, 2015). Mutation of Fgfr3 causes hearing loss and inner ear defects and might be involved in regulating the proliferation of SCs (Bermingham-McDonogh et al., 2001; White et al., 2012). Mutations in Frem2 have been linked to Fraser's syndrome, which is a rare autosomal recessive disorder with a spectrum of malformations, including malformations of the ear (Nadol et al., 2015). Mutations in Alms 1 cause Alstrom's syndrome, which is an autosomal recessive syndromic genetic disorder with sensorineural hearing loss
(Bermingham-McDonogh et al., 2001; White et al., 2012). Lif controls neural differentiation and maintenance of stem cellderived murine spiral ganglion neuron precursors (Marzella et al., 1999; Su et al., 2015). Hes1, Hes5, Hey1, and HeyL are downstream effectors of the Notch pathway and have been reported to negatively regulate $\mathrm{HC}$ differentiation and regeneration (Zheng et al., 2000; Zine et al., 2001; Li et al., 2008; Murata et al., 2009; Abdolazimi et al., 2016). Id1, Id2, and Id3 are downstream targets of the TGF $\beta$ and Hippo pathways and regulate HC formation during inner ear development (Ozeki et al., 2005; Jones et al., 2006; Laine et al., 2010; Zhan et al., 2017). These results support our hypothesis that NLPs have a much greater potential to generate HCs in the neonatal cochlea than ULPs. However, it should be noted that not all of the differentially expressed genes that we identified have been characterized, so there might still be mechanisms at work that we are not yet aware of.

\section{Cell Cycle Analysis}

Mammalian cochlear SCs do not enter the cell cycle or proliferate after birth under normal circumstances. We demonstrated that Lgr5+ progenitors that re-enter into cell cycle and proliferate could be found in the neomycin-damaged cochlea, but no such cells could be found in the control group. To identify the possible genes regulating the cell cycling of Lgr5+ progenitors, 
we compared cell cycle gene expression in NLPs and ULPs. Tfdp1 (Vairapandi et al., 2002; Yasui et al., 2003; Lu et al., 2016), which was upregulated in NLPs, is a positive regulator of the cell cycle, while Gadd45g and $S f n$, which were downregulated in NLPs, are negative regulators of the cell cycle (Liu et al., 2010; Aktary et al., 2013; Vogel and Herzinger, 2013; Phan et al., 2015). However, Cdkn1a (Duan et al., 2005; Laine et al., 2007; Mollapour et al., 2010; Laos et al., 2017), Wee1 (Lin et al., 2006; Tominaga et al., 2006; De Schutter et al., 2007; Frum et al., 2009), and Mdm2 (Helps et al., 2000; Giono and Manfredi, 2007; Shangary et al., 2008), which were upregulated in NLPs, have been reported to play roles in regulating cell proliferation, and Nek2 (Schultz et al., 1994; Fry et al., 1995; Nabilsi et al., 2013; He et al., 2016), Stmn1 (Johnsen et al., 2000; Wang et al., 2011; Li X. et al., 2015; Guo et al., 2016; Zhou et al., 2016), and Ccne2 (Chen et al., 2015; Clausse et al., 2016; Gorjala et al., 2016), which were downregulated in NLPs, have been reported to negatively regulate cell proliferation. Interestingly, these genes $(C d k n 1 a$, Mdm2, Wee1, Nek2, Stmn1, and Ccne2) are all involved in p53dependent cell cycle arrest (Fry et al., 1995; Giono and Manfredi, 2007; Kiernan, 2013; Clausse et al., 2016; Zhou et al., 2016; Laos et al., 2017), and the changes in expression of these genes might be because neomycin injury also slightly activates the p53 pathway in Lgr5+ progenitor cells. The expression changes of $T f d p 1$, Gadd45g, and Sfn promote cell cycle progression, while the expression changes of Cdkn1a, Mdm2, Wee1, Nek2, Stmn1, and Ccne2 repress cell cycle progression, which might be the reason for the lack of significant proliferation in the neomycin treated cochleae.

\section{Transcription Factor Analysis}

TFs, which bind to the promoter region of their downstream target genes and regulate gene expression, are important factors involved in development, cell proliferation, differentiation, and other cellular functions. Hes1, Hes5, Hey1, and HeyL are downstream effectors of Notch signaling, which is a well-known signaling pathway regulating $\mathrm{HC}$ fate and patterning (Malgrange et al., 2002; Li et al., 2003; Saito et al., 2009; Hartman et al., 2010; Kamaid et al., 2010; Pan et al., 2010; Jeon et al., 2011), and inhibition of Notch induces significant $\mathrm{HC}$ regeneration in newborn mice (Li et al., 2003; Kamaid et al., 2010). Id1, Id2, and $I d 3$ (inhibitors of differentiation and DNA binding) regulate $\mathrm{HC}$ formation during development by negatively regulating Atoh1 (Ozeki et al., 2005; Jones et al., 2006; Laine et al., 2010; Zhan et al., 2017). These data support our hypothesis that these TFs participate in the increased HC regeneration of NLPs. Furthermore, we have identified many TFs that have not been characterized in the inner ear before. Croxs (Calderon et al., 2012), Lcor (Yu et al., 2014), Nfil3 (Seillet et al., 2014a,b; Malishkevich et al., 2015), Adnp (Nakajima et al., 2008; Oz et al., 2012), and Tfdp1 (Vairapandi et al., 2002; Yasui et al., 2003; Lu et al., 2016) were upregulated in NLPs, and these genes have all been shown previously to have a stimulatory effect on the cell cycle or on the growth of some tumor cells and some normally proliferative tissues and/or on neurodevelopment and lymphoid cell development. Some of the TFs that were downregulated in NLPs, including Esx1 (Asanoma et al., 2015), Bhlhe41 (Cui et al.,
2016), and Dmrt1 (Krentz et al., 2009; Zou et al., 2016), have been reported to play critical roles in negatively regulating cancer cell and stem cell growth in other tissues. The involvement of these genes in the differential HC regeneration capacity of NLPs and ULPs should be investigated in the future.

\section{MicroRNA Analysis}

miRNAs bind to target mRNAs and signal their degradation, and they play a key role in the control of gene expression and the regulation of cellular differentiation, proliferation, and apoptosis. Several miRNAs have been reported to play important roles in inner ear development (Jen et al., 1997; Li et al., 2010; Wang et al., 2010; Patel and $\mathrm{Hu}, 2012)$. We found eight significantly differentially expressed microRNAs in NLPs and ULPs $(p<$ 0.05 , fold change $>2$ ). Mir466i was upregulated in NLPs, while Mir7007, mmu-mir-703, Mir107, Mir361, Mir6918, Mir6982, and Mir3099 were downregulated in NLPs. Among these miRNAs, Mir107 (Chen et al., 2013; Song et al., 2015; Xia et al., 2016; Yang et al., 2016) and Mir361 (Wu et al., 2013; Jacques et al., 2014; Chen et al., 2016; Sun et al., 2016) have been reported to suppress tumor growth and stem cell growth. However, none of the eight miRNAs have been reported previously in the inner ear and need to be further studied in the future.

\section{Signaling Pathway Analysis}

Several signaling pathways have been shown to be involved in inner ear development and $\mathrm{HC}$ regeneration (Malgrange et al., 2002; Yamamoto et al., 2006; Bermingham-McDonogh and Reh, 2011; Chai et al., 2012; Kelly et al., 2012). Among these signaling pathways, Wnt and Notch are the two most well-studied pathways in HC regeneration (Bermingham-McDonogh and Reh, 2011; Chai et al., 2012; Kelly et al., 2012). Overexpression of Wnt increases SC proliferation and Lgr5+ cell clustering and leads to increased numbers of EdU+/Lgr5-EGFP+ cells (Zhao et al., 2006; Madisen et al., 2010; Chai et al., 2012; Bohnenpoll et al., 2014). Inhibition of Notch significantly increases HC differentiation from SCs/Lgr5+ progenitors (Malgrange et al., 2002; Saito et al., 2009; Hartman et al., 2010; Pan et al., 2010; Jeon et al., 2011). Notch inhibition also increases HC regeneration through induction of the Wnt pathway (Li et al., 2003). Other pathways, such as Shh (Liu et al., 2002; Loh et al., 2014), Hippo (Murillo-Cuesta et al., 2015), and TGF $\beta$ (Kawamoto et al., 2003; Butts et al., 2005; Yang et al., 2009; McLean et al., 2017), also play important roles in inner ear development. In a recent report, a TGF $\beta$ receptor inhibitor increased Lgr5+ cell expansion in vitro (Du et al., 2013). To determine which pathways might be involved in regulating $\mathrm{HC}$ regeneration from Lgr5+ progenitors, we examined the differences in expression of pathway-related genes that might play a role in inner ear development between the NLPs and ULPs.

Hes 1, Hes5, Hey1, HeyL, and Notch4 are genes of the Notch signaling pathway, which is a well-known signaling pathway regulating $\mathrm{HC}$ fate and patterning (Zheng et al., 2000; Zine et al., 2001; Zine and de Ribaupierre, 2002; Li et al., 2008; Murata et al., 2009; Tateya et al., 2011; Korrapati et al., 2013; Ku et al., 2014; Petrovic et al., 2015; Abdolazimi et al., 2016), and were significantly downregulated in NLPs. Inhibition of 
Notch can lead to HC regeneration mainly by inducing SCs to transdifferentiate into HCs (Malgrange et al., 2002; Saito et al., 2009; Hartman et al., 2010; Pan et al., 2010; Jeon et al., 2011). Although, there is no direct evidence for regulating $\mathrm{HC}$ fate and patterning, HeyL is thought to be a target and potential Notch effector of Notch signaling (Kamaid et al., 2010; Bui et al., 2017). Notch4 is involved in the migration and invasion of several kinds of cancers (Melchor et al., 2009; Qian et al., 2016).

Five genes of the TGF $\beta$ pathway were differentially expressed. $T f d p 1$ and Bmpr2 were upregulated, while $I d 1, I d 2$, and $I d 3$ were downregulated in NLPs. $I d 1, I d 2$, and $I d 3$ regulate $\mathrm{HC}$ formation during development by negatively regulating Atoh1 (Ozeki et al., 2005; Jones et al., 2006; Laine et al., 2010; Zhan et al., 2017). Tfdp1 encodes a TF that binds to the promoter regions of a number of genes whose products are involved in cell cycle regulation or in tumor proliferation (Vairapandi et al., 2002; Yasui et al., 2003; Liu S. et al., 2016; Lu et al., 2016). Bmpr2 encodes a member of the bone morphogenetic protein receptor family of transmembrane serine/threonine kinases that play important roles in stem cell differentiation (Zeng et al., 2012; Larabee et al., 2015; RamosSolano et al., 2015). The roles of these genes in HC regeneration remain unclear and need to be studied in the future.

Six genes of the Wnt pathway were differentially expressed. Wnt7a and Fzd7 were upregulated, while Sfrp1, Ctnnbip1, Mapk10, and Dkk2 were downregulated in NLPs. Wnt7a, a gene coding for one of the Wnt genes (Chiu et al., 2010; Qu et al., 2013; King et al., 2015; Qiu et al., 2016), and Fzd7 (Sienknecht and Fekete, 2008; Yang et al., 2011; Song et al., 2014; Deng et al., 2015; Wang K. et al., 2015), one of the Wnt protein receptors, were both upregulated in NLPs and have been reported previously to be expressed in the inner ear (Wang K. et al., 2015). Wnt7 $a$ and $F z d 7$ are both reported to induce cell proliferation and differentiation in other tissues and cell types (Sienknecht and Fekete, 2008; Chiu et al., 2010; Yang et al., 2011; Song et al., 2014; Deng et al., 2015; King et al., 2015; Qiu et al., 2016), but their roles in the inner ear remain unclear and need to be further studied in the future. Sfrp1, which codes for a secreted Wnt antagonist that directly interacts with Wnt ligand (Satoh et al., 2008; Lee et al., 2010; Tong et al., 2015), is downregulated in NLPs. Ctnnbip1, which is downregulated in NLPs, encodes a protein that negatively regulates Wnt signaling by preventing the interaction between $\beta$-catenin and TCF/LEF family members (Guo et al., 2015; Qi et al., 2015; Li and Luo, 2017). Mapk10, a target of miR-27a-3p, is envolved in nasopharyngeal carcinoma cell proliferation and migration (Phillips et al., 2011). Dkk2, which is downregulated in NLPs, encodes a protein that antagonizes canonical Wnt signaling by inhibiting LRP5/6 interactions with Wnt (Mukhopadhyay et al., 2006; Fleury et al., 2010).

Six genes of the Hippo pathway were differentially expressed. Bmpr2, Fzd7, and Wnt7a were upregulated in NLPs, while Id1, $I d 2$ and $I d 3$ were downregulated in NLPs. $I d 1, I d 2$, and $I d 3$, as mentioned above, have been reported to regulate $\mathrm{HC}$ formation during inner ear development (Ozeki et al., 2005; Jones et al., 2006; Laine et al., 2010; Zhan et al., 2017). Bmpr2, as mentioned above, plays important roles in stem cell differentiation (Zeng et al., 2012; Larabee et al., 2015; Ramos-Solano et al., 2015). The roles of these genes and the Hippo pathway in HC regeneration remain unclear and need to be studied in the future.

\section{STRING Prediction of Inner Ear HC Development}

We used the GO analysis to determine the functional categories of the differentially expressed genes in NLPs and ULPs, and the STRING database was used to construct a protein-protein interaction network for the differentially expressed genes. Importantly, NLPs and ULPs have very different expressions of genes involved in inner ear development, neuron differentiation, signaling pathways, and extracellular matrix. Among the genes involved in inner ear development, Fgfr3 (BerminghamMcDonogh et al., 2001; White et al., 2012), Egfr (Saleem and Siddiqui, 2015), Frem2 (Nadol et al., 2015), Alms1 (Oshima et al., 2007b; Jagger et al., 2011), and Lif (Marzella et al., 1999; Su et al., 2015), which are all positively involved in inner ear development and HC differentiation, were upregulated in NLPs. Hes1, Hes5 (Zheng et al., 2000; Zine et al., 2001; Li et al., 2008; Murata et al., 2009; Abdolazimi et al., 2016), Hey1 (Tateya et al., 2011; Korrapati et al., 2013; Benito-Gonzalez and Doetzlhofer, 2014; Petrovic et al., 2015), HeyL (Kamaid et al., 2010), Id1, Id2, and Id3 (Ozeki et al., 2005; Jones et al., 2006; Laine et al., 2010), which all negatively regulate inner ear development and HC differentiation, were downregulated in NLPs. It would be interesting to investigate the involvement of these genes in regulating $\mathrm{HC}$ regeneration of Lgr5+ progenitor cells in the future.

In summary, we found that NLPs have a greater capacity to regenerate HCs and a slightly greater capacity to proliferate compared to ULPs. We investigated the differences in the transcriptomes between the NLPs and ULPs, and we identified several differentially expressed genes that might regulate the ability of Lgr5+ progenitor cells to proliferate and to regenerate functional HCs. Lastly, to further analyze the interactions and connections of the differentially expressed genes in HC regeneration, we constructed a STRING protein-protein interaction network. The transcriptomes of the NLPs and ULPs reported here provide numerous target genes that should be characterized for $\mathrm{HC}$ regeneration in the future.

\section{AUTHOR CONTRIBUTIONS}

SZ, HS, XG and RC designed the study. SZ, YZ, HZ, LG, XX, $\mathrm{XCZ}$, and JQ performed the laboratory experiments. RC, SZ, $\mathrm{PY}, \mathrm{YZ}, \mathrm{XLZ}, \mathrm{XQ}, \mathrm{FC}, \mathrm{HS}, \mathrm{XG}, \mathrm{YH}$, and YL contributed to critical discussion and data analysis. SZ, MW, HS, and XG and $\mathrm{RC}$ wrote the paper. All authors read and approved the final manuscript.

\section{ACKNOWLEDGMENTS}

This work was supported by grants from the Major State Basic Research Development Program of China (973 Program) (2015CB965000, 2017YFA0103900), the National Natural Science Foundation of China (Nos. 31501194, 81570913, 
81470692, 81622013, 81670938, 81371094, 81230019, 81500790, $81570921,31500852)$, the Jiangsu Province Natural Science Foundation (BK20150598, BK20150022, BK20140620, BK20160125), the Boehringer Ingelheim Pharma GmbH, the Huo Education Foundation, the Fundamental Research Funds for the Central Universities, Shanghai Municipal Education Commission-Gaofeng Clinical Medicine Grant Support (20152233), the Fundamental Research Funds for the

\section{REFERENCES}

Abdolazimi, Y., Stojanova, Z., and Segil, N. (2016). Selection of cell fate in the organ of Corti involves the integration of Hes/Hey signaling at the Atoh1 promoter. Development 143, 841-850. doi: 10.1242/dev.129320

Aktary, Z., Kulak, S., Mackey, J., Jahroudi, N., and Pasdar, M. (2013). Plakoglobin interacts with the transcription factor p53 and regulates the expression of 14-3-3sigma. J. Cell. Sci. 126(Pt 14), 3031-3042. doi: 10.1242/jcs.120642

Asanoma, K., Liu, G., Yamane, T., Miyanari, Y., Takao, T., Yagi, H., et al. (2015). Regulation of the mechanism of TWIST1 transcription by BHLHE40 and BHLHE41 in cancer cells. Mol. Cell. Biol. 35, 4096-4109. doi: 10.1128/MCB.00678-15

Balak, K. J., Corwin, J. T., and Jones, J. E. (1990). Regenerated hair cells can originate from supporting cell progeny: evidence from phototoxicity and laser ablation experiments in the lateral line system. J. Neurosci. 10, 2502-2512.

Benito-Gonzalez, A., and Doetzlhofer, A. (2014). Hey1 and Hey2 control the spatial and temporal pattern of mammalian auditory hair cell differentiation downstream of Hedgehog signaling. J. Neurosci. 34, 12865-12876. doi: 10.1523/JNEUROSCI.1494-14.2014

Bermingham-McDonogh, O., and Reh, T. A. (2011). Regulated reprogramming in the regeneration of sensory receptor cells. Neuron 71, 389-405. doi: 10.1016/j.neuron.2011.07.015

Bermingham-McDonogh, O., Stone, J. S., Reh, T. A., and Rubel, E. W. (2001). FGFR3 expression during development and regeneration of the chick inner ear sensory epithelia. Dev. Biol. 238, 247-259. doi: 10.1006/dbio.2001.0412

Bohnenpoll, T., Trowe, M. O., Wojahn, I., Taketo, M. M., Petry, M., and Kispert, A. (2014). Canonical Wnt signaling regulates the proliferative expansion and differentiation of fibrocytes in the murine inner ear. Dev. Biol. 391, 54-65. doi: 10.1016/j.ydbio.2014.03.023

Bramhall, N. F., Shi, F., Arnold, K., Hochedlinger, K., and Edge, A. S. (2014). Lgr5positive supporting cells generate new hair cells in the postnatal cochlea. Stem Cell Rep. 2, 311-322. doi: 10.1016/j.stemcr.2014.01.008

Bui, Q. T., Im, J. H., Jeong, S. B., Kim, Y. M., Lim, S. C., Kim, B., et al. (2017). Essential role of Notch4/STAT3 signaling in epithelial-mesenchymal transition of tamoxifen-resistant human breast cancer. Cancer Lett. 390, 115-125. doi: 10.1016/j.canlet.2017.01.014

Butts, S. C., Liu, W., Li, G., and Frenz, D. A. (2005). Transforming growth factorbetal signaling participates in the physiological and pathological regulation of mouse inner ear development by all-trans retinoic acid. Birth Defects Res. Part A Clin. Mol. Teratol. 73, 218-228. doi: 10.1002/bdra.20128

Calderon, M. R., Verway, M., An, B. S., DiFeo, A., Bismar, T. A., Ann, D. K., et al. (2012). Ligand-dependent corepressor (LCoR) recruitment by Kruppel-like factor 6 (KLF6) regulates expression of the cyclin-dependent kinase inhibitor CDKN1A gene. J. Biol. Chem. 287, 8662-8674. doi: 10.1074/jbc.M111.311605

Chai, R., Kuo, B., Wang, T., Liaw, E. J., Xia, A., Jan, T. A., et al. (2012). Wnt signaling induces proliferation of sensory precursors in the postnatal mouse cochlea. Proc. Natl. Acad. Sci. U.S.A. 109, 8167-8172. doi: $10.1073 /$ pnas.1202774109

Chai, R., Xia, A., Wang, T., Jan, T. A., Hayashi, T., Bermingham-McDonogh, O., et al. (2011). Dynamic expression of Lgr5, a Wnt target gene, in the developing and mature mouse cochlea. J. Assoc. Res. Otolaryngol. 12, 455-469. doi: 10.1007/s10162-011-0267-2

Chen, D., Guo, W., Qiu, Z., Wang, Q., Li, Y., Liang, L., et al. (2015). MicroRNA-30d-5p inhibits tumour cell proliferation and motility by directly
Central Universities, and the Project of Invigorating Health Care through Science Technology and Education.

\section{SUPPLEMENTARY MATERIAL}

The Supplementary Material for this article can be found online at: http://journal.frontiersin.org/article/10.3389/fnmol. 2017.00213/full\#supplementary-material

targeting CCNE2 in non-small cell lung cancer. Cancer Lett. 362, 208-217. doi: 10.1016/j.canlet.2015.03.041

Chen, L., Chen, X. R., Chen, F. F., Liu, Y., Li, P., Zhang, R., et al. (2013). MicroRNA107 inhibits U87 glioma stem cells growth and invasion. Cell. Mol. Neurobiol. 33, 651-657. doi: 10.1007/s10571-013-9927-6

Chen, W., Wang, J., Liu, S., Wang, S., Cheng, Y., Zhou, W., et al. (2016). MicroRNA-361-3p suppresses tumor cell proliferation and metastasis by directly targeting SH2B1 in NSCLC. J. Exp. Clin. Cancer Res. 35:76. doi: 10.1186/s13046-016-0357-4

Chiu, H. S., Szucsik, J. C., Georgas, K. M., Jones, J. L., Rumballe, B. A., Tang, D., et al. (2010). Comparative gene expression analysis of genital tubercle development reveals a putative appendicular Wnt7 network for the epidermal differentiation. Dev. Biol. 344, 1071-1087. doi: 10.1016/j.ydbio.2010.05.495

Clausse, V., Goloudina, A. R., Uyanik, B., Kochetkova, E. Y., Richaud, S., Fedorova, O. A., et al. (2016). Weel inhibition potentiates Wip1-dependent p53-negative tumor cell death during chemotherapy. Cell Death Dis. 7:e2195. doi: $10.1038 /$ cddis. 2016.96

Corwin, J. T., and Cotanche, D. A. (1988). Regeneration of sensory hair cells after acoustic trauma. Science 240, 1772-1774. doi: 10.1126/science.3381100

Cox, B. C., Chai, R., Lenoir, A., Liu, Z., Zhang, L., Nguyen, D. H., et al. (2014). Spontaneous hair cell regeneration in the neonatal mouse cochlea in vivo. Development 141, 816-829. doi: 10.1242/dev.103036

Cui, N., Hao, G., Zhao, Z., Wang, F., Cao, J., and Yang, A. (2016). MicroRNA224 regulates self-renewal of mouse spermatogonial stem cells via targeting DMRT1. J. Cell. Mol. Med. 20, 1503-1512. doi: 10.1111/jcmm.12838

De Schutter, K., Joubes, J., Cools, T., Verkest, A., Corellou, F., Babiychuk, E., et al. (2007). Arabidopsis WEE1 kinase controls cell cycle arrest in response to activation of the DNA integrity checkpoint. Plant Cell 19, 211-225. doi: 10.1105/tpc.106.045047

Deng, B., Zhang, Y., Zhang, S., Wen, F., Miao, Y., and Guo, K. (2015). MicroRNA142-3p inhibits cell proliferation and invasion of cervical cancer cells by targeting FZD7. Tumour Biol. 36, 8065-8073. doi: 10.1007/s13277-015-3483-2

Doetzlhofer, A., Basch, M. L., Ohyama, T., Gessler, M., Groves, A. K., and Segil, N. (2009). Hey2 regulation by FGF provides a Notch-independent mechanism for maintaining pillar cell fate in the organ of Corti. Dev. Cell 16, 58-69. doi: 10.1016/j.devcel.2008.11.008

Du, X., Li, W., Gao, X., West, M. B., Saltzman, W. M., Cheng, C. J., et al. (2013). Regeneration of mammalian cochlear and vestibular hair cells through Hes1/Hes5 modulation with siRNA. Hear. Res. 304, 91-110. doi: 10.1016/j.heares.2013.06.011

Duan, Z., Zarebski, A., Montoya-Durango, D., Grimes, H. L., and Horwitz, M. (2005). Gfil coordinates epigenetic repression of p21Cip/WAF1 by recruitment of histone lysine methyltransferase G9a and histone deacetylase 1. Mol. Cell. Biol. 25, 10338-10351. doi: 10.1128/MCB.25.23.10338-10351.2005

Duthey, B. (2013). Background Paper 6.21 Hearing Loss. Priority Medicines for Europe and the World "A Public Health Approach to Innovation." World Health Organization.

Fleury, D., Vayssiere, B., Touitou, R., Gillard, C., Lebhar, H., Rawadi, G., et al. (2010). Expression, purification and functional characterization of Wnt signaling co-receptors LRP5 and LRP6. Protein Expr. Purif. 70, 39-47. doi: 10.1016/j.pep.2009.08.012

Frum, R., Ramamoorthy, M., Mohanraj, L., Deb, S., and Deb, S. P. (2009). MDM2 controls the timely expression of cyclin A to regulate the cell cycle. Mol. Cancer Res. 7, 1253-1267. doi: 10.1158/1541-7786.MCR-08-0334 
Fry, A. M., Schultz, S. J., Bartek, J., and Nigg, E. A. (1995). Substrate specificity and cell cycle regulation of the Nek2 protein kinase, a potential human homolog of the mitotic regulator NIMA of Aspergillus nidulans. J. Biol. Chem. 270, 12899-12905. doi: 10.1074/jbc.270.21.12899

Giono, L. E., and Manfredi, J. J. (2007). Mdm2 is required for inhibition of Cdk2 activity by $\mathrm{p} 21$, thereby contributing to $\mathrm{p} 53$-dependent cell cycle arrest. Mol. Cell. Biol. 27, 4166-4178. doi: 10.1128/MCB.01967-06

Gorjala, P., Cairncross, J. G., and Gary, R. K. (2016). p53-dependent up-regulation of CDKN1A and down-regulation of CCNE2 in response to beryllium. Cell Prolif. 49, 698-709. doi: 10.1111/cpr.12291

Guo, F., Luo, Y., Mu, Y. F., Qin, S. L., Qi, Y., Qiu, Y. E., et al. (2016). miR-193b directly targets STMN1 and inhibits the malignant phenotype in colorectal cancer. Am. J. Cancer Res. 6, 2463-2475.

Guo, M., Zhang, X., Wang, G., Sun, J., Jiang, Z., Khadarian, K., et al. (2015). miR-603 promotes glioma cell growth via Wnt/beta-catenin pathway by inhibiting WIF1 and CTNNBIP1. Cancer Lett. 360, 76-86. doi: 10.1016/j.canlet.2015.02.003

Hartman, B. H., Reh, T. A., and Bermingham-McDonogh, O. (2010). Notch signaling specifies prosensory domains via lateral induction in the developing mammalian inner ear. Proc. Natl. Acad. Sci. U.S.A. 107, 15792-15797. doi: $10.1073 /$ pnas. 1002827107

He, X., Liao, Y., Lu, W., Xu, G., Tong, H., Ke, J., et al. (2016). Elevated STMN1 promotes tumor growth and invasion in endometrial carcinoma. Tumour Biol. 37, 9951-9958. doi: 10.1007/s13277-016-4869-5

Helps, N. R., Luo, X., Barker, H. M., and Cohen, P. T. (2000). NIMA-related kinase 2 (Nek2), a cell-cycle-regulated protein kinase localized to centrosomes, is complexed to protein phosphatase 1. Biochem. J. 349(Pt 2), 509-518. doi: $10.1042 / b j 3490509$

Jacques, B. E., Montgomery, W. H. IV., Uribe, P. M., Yatteau, A., Asuncion, J. D., Resendiz, G., et al. (2014). The role of Wnt/beta-catenin signaling in proliferation and regeneration of the developing basilar papilla and lateral line. Dev. Neurobiol. 74, 438-456. doi: 10.1002/dneu.22134

Jagger, D., Collin, G., Kelly, J., Towers, E., Nevill, G., Longo-Guess, C., et al. (2011). Alstrom syndrome protein ALMS1 localizes to basal bodies of cochlear hair cells and regulates cilium-dependent planar cell polarity. Hum. Mol. Genet. 20, 466-481. doi: 10.1093/hmg/ddq493

Jen, Y., Manova, K., and Benezra, R. (1997). Each member of the Id gene family exhibits a unique expression pattern in mouse gastrulation and neurogenesis. Dev. Dyn. 208, 92-106. doi: 10.1002/(SICI)1097-0177(199701)208:1<92::AID-AJA9>3.0.CO;2-X

Jeon, S. J., Fujioka, M., Kim, S. C., and Edge, A. S. (2011). Notch signaling alters sensory or neuronal cell fate specification of inner ear stem cells. J. Neurosci. 31, 8351-8358. doi: 10.1523/JNEUROSCI.6366-10.2011

Johnsen, J. I., Aurelio, O. N., Kwaja, Z., Jorgensen, G. E., Pellegata, N. S., Plattner, R., et al. (2000). p53-mediated negative regulation of stathmin/Op18 expression is associated with $\mathrm{G}(2) / \mathrm{M}$ cell-cycle arrest. Int. J. Cancer 88, 685-691. doi: 10.1002/1097-0215(20001201)88:5<685::AID-IJC1>3.0.CO;2-Z

Jones, J. M., Montcouquiol, M., Dabdoub, A., Woods, C., and Kelley, M. W. (2006). Inhibitors of differentiation and DNA binding (Ids) regulate Math1 and hair cell formation during the development of the organ of Corti. J. Neurosci. 26, 550-558. doi: 10.1523/JNEUROSCI.3859-05.2006

Kamaid, A., Neves, J., and Giraldez, F. (2010). Id gene regulation and function in the prosensory domains of the chicken inner ear: a link between Bmp signaling and Atoh1. J. Neurosci. 30, 11426-11434. doi: 10.1523/JNEUROSCI.2570-10.2010

Kawamoto, K., Yagi, M., Stover, T., Kanzaki, S., and Raphael, Y. (2003). Hearing and hair cells are protected by adenoviral gene therapy with TGF-beta1 and GDNF. Mol. Ther. 7, 484-492. doi: 10.1016/S1525-0016(03)00058-3

Kelly, M. C., Chang, Q., Pan, A., Lin, X., and Chen, P. (2012). Atoh1 directs the formation of sensory mosaics and induces cell proliferation in the postnatal mammalian cochlea in vivo. J. Neurosci. 32, 6699-6710. doi: 10.1523/JNEUROSCI.5420-11.2012

Kiernan, A. E. (2013). Notch signaling during cell fate determination in the inner ear. Semin. Cell Dev. Biol. 24, 470-479. doi: 10.1016/j.semcdb.2013.04.002

King, M. L., Lindberg, M. E., Stodden, G. R., Okuda, H., Ebers, S. D., Johnson, A., et al. (2015). WNT7A/beta-catenin signaling induces FGF1 and influences sensitivity to niclosamide in ovarian cancer. Oncogene 34, 3452-3462. doi: 10.1038/onc.2014.277
Korrapati, S., Roux, I., Glowatzki, E., and Doetzlhofer, A. (2013). Notch signaling limits supporting cell plasticity in the hair cell-damaged early postnatal murine cochlea. PLOS ONE 8:e73276. doi: 10.1371/journal.pone.0073276

Krentz, A. D., Murphy, M. W., Kim, S., Cook, M. S., Capel, B., Zhu, R., et al. (2009). The DM domain protein DMRT1 is a dose-sensitive regulator of fetal germ cell proliferation and pluripotency. Proc. Natl. Acad. Sci. U.S.A. 106, 22323-22328. doi: 10.1073/pnas.0905431106

Ku, Y. C., Renaud, N. A., Veile, R. A., Helms, C., Voelker, C. C., Warchol, M. E., et al. (2014). The transcriptome of utricle hair cell regeneration in the avian inner ear. J. Neurosci. 34, 3523-3535. doi: 10.1523/JNEUROSCI.2606-13.2014

Kuo, B. R., Baldwin, E. M., Layman, W. S., Taketo, M. M., and Zuo, J. (2015). In vivo cochlear hair cell generation and survival by coactivation of beta-catenin and Atoh1. J. Neurosci. 35, 10786-10798. doi: 10.1523/JNEUROSCI.0967-15.2015

Laine, H., Doetzlhofer, A., Mantela, J., Ylikoski, J., Laiho, M., Roussel, M. F., et al. (2007). p19(Ink4d) and p21(Cip1) collaborate to maintain the postmitotic state of auditory hair cells, their codeletion leading to DNA damage and p53-mediated apoptosis. J. Neurosci. 27, 1434-1444. doi: 10.1523/JNEUROSCI.4956-06.2007

Laine, H., Sulg, M., Kirjavainen, A., and Pirvola, U. (2010). Cell cycle regulation in the inner ear sensory epithelia: role of cyclin D1 and cyclin-dependent kinase inhibitors. Dev. Biol. 337, 134-146. doi: 10.1016/j.ydbio.2009.10.027

Laos, M., Sulg, M., Herranen, A., Anttonen, T., and Pirvola, U. (2017). Indispensable role of $\mathrm{Mdm} 2 / \mathrm{p} 53$ interaction during the embryonic and postnatal inner ear development. Sci. Rep. 7:42216. doi: 10.1038/ srep 42216

Larabee, S. M., Coia, H., Jones, S., Cheung, E., and Gallicano, G. I. (2015). miRNA17 members that target Bmpr2 influence signaling mechanisms important for embryonic stem cell differentiation in vitro and gastrulation in embryos. Stem Cells Dev. 24, 354-371. doi: 10.1089/scd.2014.0051

Lee, C. H., Hung, Y. J., Lin, C. Y., Hung, P. H., Hung, H. W., and Shieh, Y. S. (2010). Loss of SFRP1 expression is associated with aberrant beta-catenin distribution and tumor progression in mucoepidermoid carcinoma of salivary glands. Ann. Surg. Oncol. 17, 2237-2246. doi: 10.1245/s10434-010-0961-z

Lee, Y. S., Liu, F., and Segil, N. (2006). A morphogenetic wave of p27Kip1 transcription directs cell cycle exit during organ of Corti development. Development 133, 2817-2826. doi: 10.1242/dev.02453

Li, H., Kloosterman, W., and Fekete, D. M. (2010). MicroRNA-183 family members regulate sensorineural fates in the inner ear. J. Neurosci. 30, 3254-3263. doi: 10.1523/JNEUROSCI.4948-09.2010

Li, H., Liu, H., and Heller, S. (2003). Pluripotent stem cells from the adult mouse inner ear. Nat. Med. 9, 1293-1299. doi: 10.1038/nm925

Li, L., and Luo, Z. (2017). Dysregulated miR-27a-3p promotes nasopharyngeal carcinoma cell proliferation and migration by targeting Mapk10. Oncol. Rep. 37, 2679-2687. doi: 10.3892/or.2017.5544

Li, S., Mark, S., Radde-Gallwitz, K., Schlisner, R., Chin, M. T., and Chen, P. (2008). Hey2 functions in parallel with Hes1 and Hes5 for mammalian auditory sensory organ development. BMC Dev. Biol. 8:20. doi: 10.1186/1471-213X-8-20

Li, W., Wu, J., Yang, J., Sun, S., Chai, R., Chen, Z. Y., et al. (2015). Notch inhibition induces mitotically generated hair cells in mammalian cochleae via activating the Wnt pathway. Proc. Natl. Acad. Sci. U.S.A. 112, 166-171. doi: 10.1073/pnas.1415901112

Li, X., Wang, L., Li, T., You, B., Shan, Y., Shi, S., et al. (2015). STMN1 overexpression correlates with biological behavior in human cutaneous squamous cell carcinoma. Pathol. Res. Pract. 211, 816-823. doi: 10.1016/j.prp.2015.07.009

Lin, C. C., Lin, S. Y., Chung, J. G., Lin, J. P., Chen, G. W., and Kao, S. T. (2006). Down-regulation of cyclin B1 and up-regulation of Weel by berberine promotes entry of leukemia cells into the G2/M-phase of the cell cycle. Anticancer Res. 26, 1097-1104.

Liu, L., Chen, Y., Qi, J., Zhang, Y., He, Y., Ni, W., et al. (2016). Wnt activation protects against neomycin-induced hair cell damage in the mouse cochlea. Cell Death Dis. 7:e2136. doi: 10.1038/cddis.2016.35

Liu, Q., Basu, S., Qiu, Y., Tang, F., and Dong, F. (2010). A role of Miz-1 in Gfi1-mediated transcriptional repression of CDKN1A. Oncogene 29, 2843-2852. doi: $10.1038 /$ onc. 2010.48

Liu, S., Sun, G., Yuan, B., Zhang, L., Gao, Y., Jiang, H., et al. (2016). miR-375 negatively regulates porcine preadipocyte differentiation by targeting BMPR2. FEBS Lett. 590, 1417-1427. doi: 10.1002/1873-3468.12169 
Liu, W., Li, G., Chien, J. S., Raft, S., Zhang, H., Chiang, C., et al. (2002). Sonic hedgehog regulates otic capsule chondrogenesis and inner ear development in the mouse embryo. Dev. Biol. 248, 240-250. doi: 10.1006/dbio.2002.0733

Loh, S. L., Teh, C., Muller, J., Guccione, E., Hong, W., and Korzh, V. (2014). Zebrafish yap1 plays a role in differentiation of hair cells in posterior lateral line. Sci. Rep. 4:4289. doi: 10.1038/srep04289

Lu, X., Lv, X. D., Ren, Y. H., Yang, W. D., Li, Z. B., Zhang, L., et al. (2016). Dysregulation of TFDP1 and of the cell cycle pathway in highgrade glioblastoma multiforme: a bioinformatic analysis. Genet. Mol. Res. 15:gmr7646. doi: 10.4238/gmr.15027646

Ma, E. Y., Rubel, E. W., and Raible, D. W. (2008). Notch signaling regulates the extent of hair cell regeneration in the zebrafish lateral line. J. Neurosci. 28, 2261-2273. doi: 10.1523/JNEUROSCI.4372-07.2008

Madisen, L., Zwingman, T. A., Sunkin, S. M., Oh, S. W., Zariwala, H. A., $\mathrm{Gu}, \mathrm{H}$., et al. (2010). A robust and high-throughput Cre reporting and characterization system for the whole mouse brain. Nat. Neurosci. 13, 133-140. doi: $10.1038 / \mathrm{nn} .2467$

Mahmoodian Sani, M. R., Hashemzadeh-Chaleshtori, M., Saidijam, M., Jami, M. S., and Ghasemi-Dehkordi, P. (2016). MicroRNA-183 family in inner ear: hair cell development and deafness. J. Audiol. Otol. 20, 131-138. doi: 10.7874/jao.2016.20.3.131

Malgrange, B., Belachew, S., Thiry, M., Nguyen, L., Rogister, B., Alvarez, M. L., et al. (2002). Proliferative generation of mammalian auditory hair cells in culture. Mech. Dev. 112, 79-88. doi: 10.1016/S0925-4773(01)00642-6

Malishkevich, A., Leyk, J., Goldbaum, O., Richter-Landsberg, C., and Gozes, I. (2015). ADNP/ADNP2 expression in oligodendrocytes: implication for myelin-related neurodevelopment. J. Mol. Neurosci. 57, 304-313. doi: 10.1007/s12031-015-0640-4

Martinez-Monedero, R., Yi, E., Oshima, K., Glowatzki, E., and Edge, A. S. (2008). Differentiation of inner ear stem cells to functional sensory neurons. Dev. Neurobiol. 68, 669-684. doi: 10.1002/dneu.20616

Marzella, P. L., Gillespie, L. N., Clark, G. M., Bartlett, P. F., and Kilpatrick, T. J. (1999). The neurotrophins act synergistically with LIF and members of the TGF-beta superfamily to promote the survival of spiral ganglia neurons in vitro. Hear. Res. 138, 73-80. doi: 10.1016/S0378-5955(99)00152-5

McLean, W. J., Yin, X., Lu, L., Lenz, D. R., McLean, D., Langer, R., et al. (2017). Clonal expansion of Lgr5-positive cells from mammalian cochlea and high-purity generation of sensory hair cells. Cell Rep. 18, 1917-1929. doi: 10.1016/j.celrep.2017.01.066

Melchor, L., Saucedo-Cuevas, L. P., Munoz-Repeto, I., Rodriguez-Pinilla, S. M., Honrado, E., Campoverde, A., et al. (2009). Comprehensive characterization of the DNA amplification at $13 \mathrm{q} 34$ in human breast cancer reveals TFDP1 and CUL4A as likely candidate target genes. Breast Cancer Res. 11:R86. doi: $10.1186 /$ bcr 2456

Mollapour, M., Tsutsumi, S., and Neckers, L. (2010). Hsp90 phosphorylation, Wee1 and the cell cycle. Cell Cycle 9, 2310-2316. doi: 10.4161/cc.9.12.12054

Mukhopadhyay, M., Gorivodsky, M., Shtrom, S., Grinberg, A., Niehrs, C., Morasso, M. I., et al. (2006). Dkk2 plays an essential role in the corneal fate of the ocular surface epithelium. Development 133, 2149-2154. doi: $10.1242 /$ dev.02381

Murata, J., Ohtsuka, T., Tokunaga, A., Nishiike, S., Inohara, H., Okano, H., et al. (2009). Notch-Hes1 pathway contributes to the cochlear prosensory formation potentially through the transcriptional down-regulation of p27Kip1. J. Neurosci. Res. 87, 3521-3534. doi: 10.1002/jnr.22169

Murillo-Cuesta, S., L., Rodriguez-de la Rosa, Contreras, J., Celaya, A. M., Camarero, G., Rivera, T., et al. (2015). Transforming growth factor betal inhibition protects from noise-induced hearing loss. Front. Aging Neurosci. 7:32. doi: 10.3389/fnagi.2015.00032

Nabilsi, N. H., Ryder, D. J., Peraza-Penton, A. C., Poudyal, R., Loose, D. S., and Kladde, M. P. (2013). Local depletion of DNA methylation identifies a repressive p53 regulatory region in the NEK2 promoter. J. Biol. Chem. 288, 35940-35951. doi: 10.1074/jbc.M113.523837

Nadol, J. B. Jr., Marshall, J. D., and Bronson, R. T. (2015). Histopathology of the human inner ear in Alstrom's syndrome. Audiol. Neurootol. 20, 267-272. doi: $10.1159 / 000381935$

Nakajima, J., Ishikawa, S., Hamada, J., Yanagihara, M., Koike, T., and Hatakeyama, M. (2008). Anti-tumor activity of ESX1 on cancer cells harboring oncogenic K-ras mutation. Biochem. Biophys. Res. Commun. 370, 189-194. doi: 10.1016/j.bbrc.2008.03.062

Ni, W., Zeng, S., Li, W., Chen, Y., Zhang, S., Tang, M., et al. (2016). Wnt activation followed by Notch inhibition promotes mitotic hair cell regeneration in the postnatal mouse cochlea. Oncotarget 7, 66754-66768. doi: 10.18632/oncotarget.11479

Oesterle, E. C., Campbell, S., Taylor, R. R., Forge, A., and Hume, C. R. (2008). Sox2 and JAGGED1 expression in normal and drug-damaged adult mouse inner ear. J. Assoc. Res. Otolaryngol. 9, 65-89. doi: 10.1007/s10162-007-0106-7

Oshima, K., Grimm, C. M., Corrales, C. E., Senn, P., Martinez Monedero, R., Geleoc, G. S., et al. (2007a). Differential distribution of stem cells in the auditory and vestibular organs of the inner ear. J. Assoc. Res. Otolaryngol. 8, 18-31. doi: 10.1007/s10162-006-0058-3

Oshima, K., Teo, D. T., Senn, P., Starlinger, V., and Heller, S. (2007b). LIF promotes neurogenesis and maintains neural precursors in cell populations derived from spiral ganglion stem cells. BMC Dev. Biol. 7:112. doi: 10.1186/1471-213X-7-112

Oz, S., Ivashko-Pachima, Y., and Gozes, I. (2012). The ADNP derived peptide, NAP modulates the tubulin pool: implication for neurotrophic and neuroprotective activities. PLoS ONE 7:e51458. doi: 10.1371/journal.pone.0051458

Ozeki, M., Schlentz, E. P., and Lin, J. (2005). Characterization of inhibitor of differentiation (Id3) gene expression in the developing cochlear tissue of rats. Acta Otolaryngol. 125, 244-249. doi: 10.1080/00016480510027105

Pan, W., Jin, Y., Stanger, B., and Kiernan, A. E. (2010). Notch signaling is required for the generation of hair cells and supporting cells in the mammalian inner ear. Proc. Natl. Acad. Sci. U.S.A. 107, 15798-15803. doi: 10.1073/pnas.1003089107

Pannier, S., Couloigner, V., Messaddeq, N., Elmaleh-Berges, M., Munnich, A., Romand, R., et al. (2009). Activating Fgfr3 Y367C mutation causes hearing loss and inner ear defect in a mouse model of chondrodysplasia. Biochim. Biophys. Acta 1792, 140-147. doi: 10.1016/j.bbadis.2008.11.010

Patel, M., and Hu, B. H. (2012). MicroRNAs in inner ear biology and pathogenesis. Hear. Res. 287, 6-14. doi: 10.1016/j.heares.2012.03.008

Petrovic, J., Galvez, H., Neves, J., Abello, G., and Giraldez, F. (2015). Differential regulation of Hes/Hey genes during inner ear development. Dev. Neurobiol. 75, 703-720. doi: 10.1002/dneu.22243

Phan, L., Chou, P. C., Velazquez-Torres, G., Samudio, I., Parreno, K., Huang, Y., et al. (2015). The cell cycle regulator 14-3-3sigma opposes and reverses cancer metabolic reprogramming. Nat. Commun. 6:7530. doi: 10.1038/ncomms8530

Phillips, M. D., Mukhopadhyay, M., Poscablo, C., and Westphal, H. (2011). Dkk1 and Dkk2 regulate epicardial specification during mouse heart development. Int. J. Cardiol. 150, 186-192. doi: 10.1016/j.ijcard.2010.04.007

Qi, W., Chen, J., Cheng, X., Huang, J., Xiang, T., Li, Q., et al. (2015). Targeting the Wnt-regulatory protein CTNNBIP1 by microRNA-214 enhances the stemness and self-renewal of cancer stem-like cells in lung adenocarcinomas. Stem Cells 33, 3423-3436. doi: 10.1002/stem.2188

Qian, C. J., Chen, Y. Y., Zhang, X., Liu, F. Q., Yue, T. T., Ye, B., et al. (2016). Notch4 inhibition reduces migration and invasion and enhances sensitivity to docetaxel by inhibiting Akt/fascin in pancreatic cancer cells. Oncol. Lett. 12, 3499-3505. doi: 10.3892/ol.2016.5097

Qiu, X., Jiao, J., Li, Y., and Tian, T. (2016). Overexpression of FZD7 promotes glioma cell proliferation by upregulating TAZ. Oncotarget 7, 85987-85999. doi: 10.18632/oncotarget.13292

Qu, Q., Sun, G., Murai, K., Ye, P., Li, W., Asuelime, G., et al. (2013). Wnt7a regulates multiple steps of neurogenesis. Mol. Cell. Biol. 33, 2551-2559. doi: 10.1128/MCB.00325-13

Ramos-Solano, M., Meza-Canales, I. D., Torres-Reyes, L. A., Alvarez-Zavala, M., Alvarado-Ruiz, L., Rincon-Orozco, B., et al. (2015). Expression of WNT genes in cervical cancer-derived cells: implication of WNT7A in cell proliferation and migration. Exp. Cell Res. 335, 39-50. doi: 10.1016/j.yexcr.2015.05.001

Saito, R., Yamasaki, T., Nagai, Y., Wu, J., Kajiho, H., Yokoi, T., et al. (2009). CrxOS maintains the self-renewal capacity of murine embryonic stem cells. Biochem. Biophys. Res. Commun. 390, 1129-1135. doi: 10.1016/j.bbrc.2009.09.118

Saleem, A. A., and Siddiqui, S. N. (2015). Fraser Syndrome. J. Coll. Physicians Surg. Pak. 25(Suppl. 2), S124-S126. doi: 10.2015/JCPSP.S124S126

Satoh, W., Matsuyama, M., Takemura, H., Aizawa, S., and Shimono, A. (2008). Sfrp1, Sfrp2, and Sfrp5 regulate the Wnt/beta-catenin and the planar cell polarity pathways during early trunk formation in mouse. Genesis 46, 92-103. doi: $10.1002 / \mathrm{dvg} .20369$ 
Schultz, S. J., Fry, A. M., Sutterlin, C., Ried, T., and Nigg, E. A. (1994). Cell cycledependent expression of Nek2, a novel human protein kinase related to the NIMA mitotic regulator of Aspergillus nidulans. Cell Growth Differ. 5, 625-635.

Seillet, C., Huntington, N. D., Gangatirkar, P., Axelsson, E., Minnich, M., Brady, H. J., et al. (2014a). Differential requirement for Nfil3 during NK cell development. J. Immunol. 192, 2667-2676. doi: 10.4049/jimmunol.1302605

Seillet, C., Rankin, L. C., Groom, J. R., Mielke, L. A., Tellier, J., Chopin, M., et al. (2014b). Nfil3 is required for the development of all innate lymphoid cell subsets. J. Exp. Med. 211, 1733-1740. doi: 10.1084/jem.20140145

Shangary, S., Ding, K., Qiu, S., Nikolovska-Coleska, Z., Bauer, J. A., Liu, M., et al. (2008). Reactivation of p53 by a specific MDM2 antagonist (MI-43) leads to p21-mediated cell cycle arrest and selective cell death in colon cancer. Mol. Cancer Ther. 7, 1533-1542. doi: 10.1158/1535-7163.MCT-08-0140

Shi, F., Hu, L., and Edge, A. S. (2013). Generation of hair cells in neonatal mice by beta-catenin overexpression in Lgr5-positive cochlear progenitors. Proc. Natl. Acad. Sci. U.S.A. 110, 13851-13856. doi: 10.1073/pnas.1219952110

Shi, F., Kempfle, J. S., and Edge, A. S. (2012). Wnt-responsive Lgr5-expressing stem cells are hair cell progenitors in the cochlea. J. Neurosci. 32, 9639-9648. doi: 10.1523/JNEUROSCI.1064-12.2012

Sienknecht, U. J., and Fekete, D. M. (2008). Comprehensive Wnt-related gene expression during cochlear duct development in chicken. J. Comp. Neurol. 510, 378-395. doi: 10.1002/cne.21791

Sinkkonen, S. T., Chai, R., Jan, T. A., Hartman, B. H., Laske, R. D., Gahlen, F., et al. (2011). Intrinsic regenerative potential of murine cochlear supporting cells. Sci. Rep. 1:26. doi: $10.1038 /$ srep00026

Song, J., Gao, L., Yang, G., Tang, S., Xie, H., Wang, Y., et al. (2014). MiR199a regulates cell proliferation and survival by targeting FZD7. PLOS ONE 9:e110074. doi: 10.1371/journal.pone.0110074

Song, N., Ma, X., Li, H., Zhang, Y., Wang, X., Zhou, P., et al. (2015). microRNA-107 functions as a candidate tumor suppressor gene in renal clear cell carcinoma involving multiple genes. Urol. Oncol. 33, 205.e1-205.e11. doi: 10.1016/j.urolonc.2015.02.003

Stone, J. S., and Cotanche, D. A. (2007). Hair cell regeneration in the avian auditory epithelium. Int. J. Dev. Biol. 51, 633-647. doi: 10.1387/ijdb.072408js

Su, Y. X., Hou, C. C., and Yang, W. X. (2015). Control of hair cell development by molecular pathways involving Atoh1, Hes1 and Hes5. Gene 558, 6-24. doi: 10.1016/j.gene.2014.12.054

Sun, J. J., Chen, G. Y., and Xie, Z. T. (2016). MicroRNA-361-5p inhibits cancer cell growth by targeting CXCR6 in hepatocellular carcinoma. Cell. Physiol. Biochem. 38, 777-785. doi: 10.1159/000443033

Tateya, T., Imayoshi, I., Tateya, I., Ito, J., and Kageyama, R. (2011). Cooperative functions of Hes/Hey genes in auditory hair cell and supporting cell development. Dev. Biol. 352, 329-340. doi: 10.1016/j.ydbio.2011.01.038

Tominaga, Y., Li, C., Wang, R. H., and Deng, C. X. (2006). Murine Weel plays a critical role in cell cycle regulation and pre-implantation stages of embryonic development. Int. J. Biol. Sci. 2, 161-170. doi: 10.7150/ijbs.2.161

Tong, Y. Q., Liu, B., Zheng, H. Y., Gu, J., Liu, H., Li, F., et al. (2015). MiR-215, an activator of the CTNNBIP1/beta-catenin pathway, is a marker of poor prognosis in human glioma. Oncotarget 6, 25024-25033. doi: 10.18632 /oncotarget. 4622

Vairapandi, M., Balliet, A. G., Hoffman, B., and Liebermann, D. A. (2002). GADD45b and GADD45g are cdc2/cyclinB1 kinase inhibitors with a role in $\mathrm{S}$ and G2/M cell cycle checkpoints induced by genotoxic stress. J. Cell. Physiol. 192, 327-338. doi: 10.1002/jcp.10140

Vogel, S., and Herzinger, T. (2013). The epithelium specific cell cycle regulator 14-3-3sigma is required for preventing entry into mitosis following ultraviolet B. Photodermatol. Photoimmunol. Photomed. 29, 300-310. doi: 10.1111/phpp.12071

Wang, K., Xie, D., Xie, J., Wan, Y., Ma, L., Qi, X., et al. (2015). MiR-27a regulates Wnt/beta-catenin signaling through targeting SFRP1 in glioma. Neuroreport 26, 695-702. doi: 10.1097/WNR.0000000000000410

Wang, R., Wang, Z., Yang, J., Liu, X., Wang, L., Guo, X., et al. (2011). LRRC4 inhibits the proliferation of human glioma cells by modulating the expression of STMN1 and microtubule polymerization. J. Cell. Biochem. 112, 3621-3629. doi: $10.1002 / j c b .23293$

Wang, T., Chai, R., Kim, G. S., Pham, N., Jansson, L., Nguyen, D. H., et al. (2015). Lgr5+ cells regenerate hair cells via proliferation and direct transdifferentiation in damaged neonatal mouse utricle. Nat. Commun. 6, 6613. doi: $10.1038 /$ ncomms 7613

Wang, X. R., Zhang, X. M., Zhen, J., Zhang, P. X., Xu, G., and Jiang, H. (2010). MicroRNA expression in the embryonic mouse inner ear. Neuroreport 21, 611-617. doi: 10.1097/WNR.0b013e328338864b

Waqas, M., Guo, L., Zhang, S., Chen, Y., Zhang, X., Wang, L., et al. (2016a). Characterization of Lgr5+ progenitor cell transcriptomes in the apical and basal turns of the mouse cochlea. Oncotarget 7, 41123-41141. doi: 10.18632/oncotarget.8636

Waqas, M., Zhang, S., He, Z., Tang, M., and Chai, R. (2016b). Role of Wnt and Notch signaling in regulating hair cell regeneration in the cochlea. Front. Med. 10, 237-249. doi: 10.1007/s11684-016-0464-9

Warchol, M. E. (2011). Sensory regeneration in the vertebrate inner ear: differences at the levels of cells and species. Hear. Res. 273, 72-79. doi: 10.1016/j.heares.2010.05.004

White, P. M., Doetzlhofer, A., Lee, Y. S., Groves, A. K., and Segil, N. (2006). Mammalian cochlear supporting cells can divide and trans-differentiate into hair cells. Nature 441, 984-987. doi: 10.1038/nature04849

White, P. M., Stone, J. S., Groves, A. K., and Segil, N. (2012). EGFR signaling is required for regenerative proliferation in the cochlea: conservation in birds and mammals. Dev. Biol. 363, 191-200. doi: 10.1016/j.ydbio.2011.12.035

Wu, X., Xi, X., Yan, Q., Zhang, Z., Cai, B., Lu, W., et al. (2013). MicroRNA-361$5 \mathrm{p}$ facilitates cervical cancer progression through mediation of epithelial-tomesenchymal transition. Med. Oncol. 30:751. doi: 10.1007/s12032-013-0751-0

Xia, H., Li, Y., and Lv, X. (2016). MicroRNA-107 inhibits tumor growth and metastasis by targeting the BDNF-mediated PI3K/AKT pathway in human non-small lung cancer. Int. J. Oncol. 49, 1325-1333. doi: 10.3892/ijo.2016.3628

Yamamoto, N., Tanigaki, K., Tsuji, M., Yabe, D., Ito, J., and Honjo, T. (2006). Inhibition of Notch/RBP-J signaling induces hair cell formation in neonate mouse cochleas. J. Mol. Med. 84, 37-45. doi: 10.1007/s00109-005-0706-9

Yang, L., Wu, X., Wang, Y., Zhang, K., Wu, J., Yuan, Y. C., et al. (2011). FZD7 has a critical role in cell proliferation in triple negative breast cancer. Oncogene 30, 4437-4446. doi: 10.1038/onc.2011.145

Yang, S. M., Guo, W. W., Hu, Y. Y., Sun, Y. X., Hou, Z. H., Sun, J. H., et al. (2009). Smad5 haploinsufficiency leads to hair cell and hearing loss. Dev. Neurobiol. 69, 153-161. doi: 10.1002/dneu.20692

Yang, S., Zhang, Y., Zhao, X., Wang, J., and Shang, J. (2016). microRNA-361 targets Wilms' tumor 1 to inhibit the growth, migration and invasion of non-small-cell lung cancer cells. Mol. Med. Rep. 14, 5415-5421. doi: 10.3892/mmr.2016.5858

Yasui, K., Okamoto, H., Arii, S., and Inazawa, J. (2003). Association of overexpressed TFDP1 with progression of hepatocellular carcinomas. J. Hum. Genet. 48, 609-613. doi: 10.1007/s10038-003-0086-3

Yu, X., Wang, Y., Deng, M., Li, Y., Ruhn, K. A., Zhang, C. C., et al. (2014). The basic leucine zipper transcription factor NFIL3 directs the development of a common innate lymphoid cell precursor. Elife 3:e04406. doi: 10.7554/eLife.04406

Zeng, Y., Qu, X., Li, H., Huang, S., Wang, S., Xu, Q., et al. (2012). MicroRNA-100 regulates osteogenic differentiation of human adipose-derived mesenchymal stem cells by targeting BMPR2. FEBS Lett. 586, 2375-2381. doi: 10.1016/j.febslet.2012.05.049

Zhan, W., Wang, W., Han, T., Xie, C., Zhang, T., Gan, M., et al. (2017) COMMD9 promotes TFDP1/E2F1 transcriptional activity via interaction with TFDP1 in non-small cell lung cancer. Cell. Signal. 30, 59-66. doi: 10.1016/j.cellsig.2016.11.016

Zhao, Y., Wang, Y., Wang, Z., Liu, H., Shen, Y., Li, W., et al. (2006). Sonic hedgehog promotes mouse inner ear progenitor cell proliferation and hair cell generation in vitro. Neuroreport 17, 121-124. doi: 10.1097/01.wnr.0000198439.44 636.49

Zheng, J. L., and Gao, W. Q. (2000). Overexpression of Math1 induces robust production of extra hair cells in postnatal rat inner ears. Nat. Neurosci. 3 , 580-586. doi: $10.1038 / 75753$

Zheng, J. L., Shou, J., Guillemot, F., Kageyama, R., and Gao, W. Q. (2000). Hes1 is a negative regulator of inner ear hair cell differentiation. Development 127, 4551-4560.

Zhou, J., Ju, W. Q., Yuan, X. P., Zhu, X. F., Wang, D. P., and He, X. S. (2016). miR-26a regulates mouse hepatocyte proliferation via directly targeting the $3^{\prime}$ untranslated region of CCND2 and CCNE2. Hepatobiliary Pancreat. Dis. Int. 15, 65-72. doi: 10.1016/S1499-3872(15)60383-6 
Zine, A., and de Ribaupierre, F. (2002). Notch/Notch ligands and Math1 expression patterns in the organ of Corti of wild-type and Hes1 and Hes5 mutant mice. Hear. Res. 170, 22-31. doi: 10.1016/S0378-5955(02)00449-5

Zine, A., Aubert, A., Qiu, J., Therianos, S., Guillemot, F., Kageyama, R., et al. (2001). Hes1 and Hes5 activities are required for the normal development of the hair cells in the mammalian inner ear. J. Neurosci. 21, $4712-4720$.

Zou, C. D., Zhao, W. M., Wang, X. N., Li, Q., Huang, H., Cheng, W. P., et al. (2016). MicroRNA-107: a novel promoter of tumor progression that targets the CPEB3/EGFR axis in human hepatocellular carcinoma. Oncotarget 7, 266-278. doi: 10.18632/oncotarget.5689
Conflict of Interest Statement: The authors declare that the research was conducted in the absence of any commercial or financial relationships that could be construed as a potential conflict of interest.

Copyright $\odot 2017$ Zhang, Zhang, Yu, Hu, Zhou, Guo, Xu, Zhu, Waqas, Qi, Zhang, Liu, Chen, Tang, Qian, Shi, Gao and Chai. This is an open-access article distributed under the terms of the Creative Commons Attribution License (CC BY). The use, distribution or reproduction in other forums is permitted, provided the original author(s) or licensor are credited and that the original publication in this journal is cited, in accordance with accepted academic practice. No use, distribution or reproduction is permitted which does not comply with these terms. 